\title{
Aquatic invertebrate assemblages of wetlands and rivers in the wheatbelt region of Western Australia
}

\author{
A.M. Pinder ${ }^{1}$, S.A. Halse ${ }^{1}$, J.M. McRae ${ }^{1}$ and R.J. Shiel ${ }^{2}$ \\ ${ }^{1}$ Science Division, Department of Conservation and Land Management, \\ P.O. Box 51 Wanneroo, Western Australia 6946, Australia \\ ${ }^{2}$ Department of Environmental Biology, University of Adelaide, South Australia 5005, Australia
}

\begin{abstract}
A biological survey of wetlands in the Wheatbelt and adjacent coastal areas of south-west Western Australia was undertaken to document the extent and distribution of the region's aquatic invertebrate diversity. Two hundred and thirty samples were collected from 223 wetlands, including freshwater swamps and lakes, salinised wetlands, springs, rivers, artificial wetlands (farm dams and small reservoirs), saline playas and coastal salt lakes between 1997 and 2000. The number of aquatic invertebrates identified from the region has been increased five-fold to almost 1000 species, of which $10 \%$ are new and known to date only from the Wheatbelt, and another $7 \%$ (mostly rotifers and cladocerans) are recorded in Western Australia for the first time. The survey has provided further evidence of a significant radiation of microcrustaceans in south-west Western Australia. Comparison of the fauna with other regions suggests that saline playas and ephemeral pools on granite outcrop support most of the species likely to be restricted to the Wheatbelt. Most species were collected infrequently, but for many of the least common species the Wheatbelt is likely to be on the periphery of their range.

Cluster analysis was used to identify 10 assemblages of species with similar patterns of occurrence. Richness of these assemblages was best predicted by salinity and climate variables, or by physical habitat characteristics (granite outcrop pools, flowing water), although the amount of variation explained by models was variable ( $R^{2} 0.36$ to 0.79 ). Fourteen groups of wetlands were recognised from cluster analysis of sites based on community composition. Wetlands of these groups differed primarily in their physical habitat, salinity, degree of secondary salinisation, $\mathrm{pH}$ and their occurrence across geographic and climatic gradients. Some assemblages were closely associated with particular wetland groups but others occurred across a range of wetland types. Salinity was identified as the primary influence on the occurrence of aquatic invertebrates in the Wheatbelt, although other variables are important in particular situations.

Secondary salinisation dramatically alters composition and richness of freshwater aquatic invertebrate communities, involving gradual replacement of salt sensitive species by a smaller set of salt tolerant and halophilic species as salinity increases. These altered communities are relatively homogeneous compared with those of freshwater or naturally saline wetlands. Communities of naturally saline wetlands are comprised of a heterogeneous array of halophilic species, but these communities and species are also threatened by altered hydrology and chemistry associated with dryland salinity.
\end{abstract}

\section{INTRODUCTION}

The Wheatbelt region of south-west Western Australia occupies some $220000 \mathrm{~km}^{2}$ between the south-west forests and the more arid regions to the north and east and is approximately bounded by the 300 and $600 \mathrm{~mm}$ annual rainfall isohyets (Figure 1). Long renowned for the richness and endemism of its flora (Hopper, 1979), the region is also unique in terms of the extent and severity of dryland salinity (NLWRA, 2001; Short and McConnell, 2001; Williams, 1987,1999). Extensive clearing of native vegetation has resulted in severe hydrological imbalance and, as a consequence, agricultural and natural environments are being adversely affected by rising groundwater, increased salinity and associated problems (Clarke et al., 2002). The Western Australian Salinity Action Plan (Anonymous, 1996) highlighted the likely detrimental impact of these processes on biodiversity but also noted that effective prioritisation of conservation activities was hampered by inadequate knowledge of the diversity and biogeographic patterning of the region's biota. To address this information gap, one 
of the major undertakings of the Salinity Action Plan was a biological survey of the Wheatbelt. The aims of the survey were 1) to document the extent and distribution of the region's floral and faunal diversity, 2) to investigate abiotic influences on community composition and occurrence of species assemblages and 3) to provide data to assist with selection of high biodiversity catchments for the Natural Diversity Recovery Catchment program (Anonymous, 1996). This paper on the region's aquatic invertebrate fauna is one of a series arising from the survey (see other papers in this volume). The survey was supplemented by data from a separate wetland monitoring project (Cale et al., 2004), also part of the Salinity Action Plan.

The Wheatbelt has both a very large number and a considerable diversity of wetlands (Halse et al., 1992; Pen, 1997) but the aquatic invertebrate assemblages inhabiting these are poorly documented. While there have been several previous studies of aquatic invertebrates in the region, these have been of limited geographic scope or low taxonomic resolution or have focussed on particular habitats or taxa (Bayly, 1997; Brock and Shiel, 1983; Doupé and Horwitz, 1995; Geddes et al., 1981; Halse, 1981; Halse, Pearson et al., 2000; Kay et al., 2001; Koste et al., 1983; Rippingale, 1981). These, together with various taxonomic works, collectively identified around 200 taxa in the Wheatbelt. In this paper we aim to describe more fully the region's aquatic invertebrate fauna, categorize wetlands on the basis of their invertebrate communities and relate the distribution of the fauna to environmental attributes, including secondary salinisation. Elsewhere in this volume, Lyons et al. (2004) present a similar analysis of wetland flora and Halse et al. (2004) examine conservation priorities for Wheatbelt wetlands in a combined analysis of waterbirds, aquatic invertebrates and wetland plants. In addition, Pinder et al. $(2000,2002)$ recently examined particular components of the aquatic invertebrate fauna (those inhabiting granite outcrop pools and those restricted to salt lakes) and Blinn et al. (2004) compared distributional patterns of diatoms and microinvertebrates from a sub-set of the wetlands studied here. Finally, Halse et al. (2003) examined the prospects for Wheatbelt aquatic biodiversity in the face of salinisation and Pinder et al. (2005) provided a more detailed review of salinity tolerance within the region's aquatic invertebrate fauna.

\section{STUDY AREA AND METHODS}

\section{Extent}

This survey was centred on the Wheatbelt region of south-west Western Australia, essentially the Avon-Wheatbelt and Mallee bioregions of Thackway and Cresswell (1995), but extended to the south and north coasts to include the Esperance Sandplains and Geraldton Sandplains bioregions and into the eastern part of the Jarrah Forest (Figure 1). The most northerly and easterly sites surveyed were reaches of the Murchison and Thomas Rivers respectively, while wetlands of the Lake Muir complex were the most south-westerly.

\section{Geology and hydrology}

The study area has a largely granitic/gneissic basement geology, dominated by the Archaean Yilgarn Craton inland with Permian granites underlying the Geraldton Sandplains and parts of the Esperance Sandplains (Geological Survey of Western Australia, 1990). The Yilgarn Craton is a deeply weathered plateau of low relief (mostly 300 to $600 \mathrm{~m} \mathrm{ASL}$ ), poorly drained by an extensive system of in-filled palaeovalleys that constitute the episodically flowing upper catchments of the major rivers (Blackwood, Swan-Avon and Moore) (Beard, 1997; Commander et al., 2002; George, 1992). These systems consist of broad vegetated flats (up to 15 $\mathrm{km}$ wide) with shallow braided channels, mosaics of thousands of wetlands and associated alluvial aquifers. Most of these wetlands are naturally saline playas that vary in size from less than a hectare to over $100 \mathrm{~km}^{2}$ and become increasingly saline and seasonal with distance from the coast. Freshwater wetlands, mostly seasonal claypans and vegetated swamps, are also common on the plateau but tend to occur higher in the landscape or in the higher rainfall south-western areas. West of the Meckering Line (Figure 1) drainage lines are better defined and flow is more reliably seasonal. Valleys are also more incised along the south coast, so the Esperance Sandplains and the southern edge of the Mallee bioregion are relatively well drained by short seasonal rivers flowing into seasonally to permanently closed estuaries (Beard, 1999; Hodgkin and Hesp, 1998). Lentic waters in this region include seasonal freshwater swamps, playas in the upper catchments of some rivers, and wetlands formed by coastal processes, the latter including semi-permanent to permanent lakes. The Geraldton Sandplains bioregion has a variety of seasonal to semi-permanent freshwater swamps and lakes, numerous springs, a line of salt lakes near the coast and a number of fresh to moderately saline seasonal rivers. Many of the latter are short and arise within the bioregion, but some originate further inland, and some become subterranean or enter coastal lakes or semi-closed estuaries rather than discharging directly to the sea.

Most wetlands in the study area interact strongly with groundwater which is contained in semiconfined regional aquifers (within the partiallyweathered zone above bedrock), or in local ephemeral aquifers perched on clayey subsoils, or in aquifers in the alluvial and lacustrine sediments 


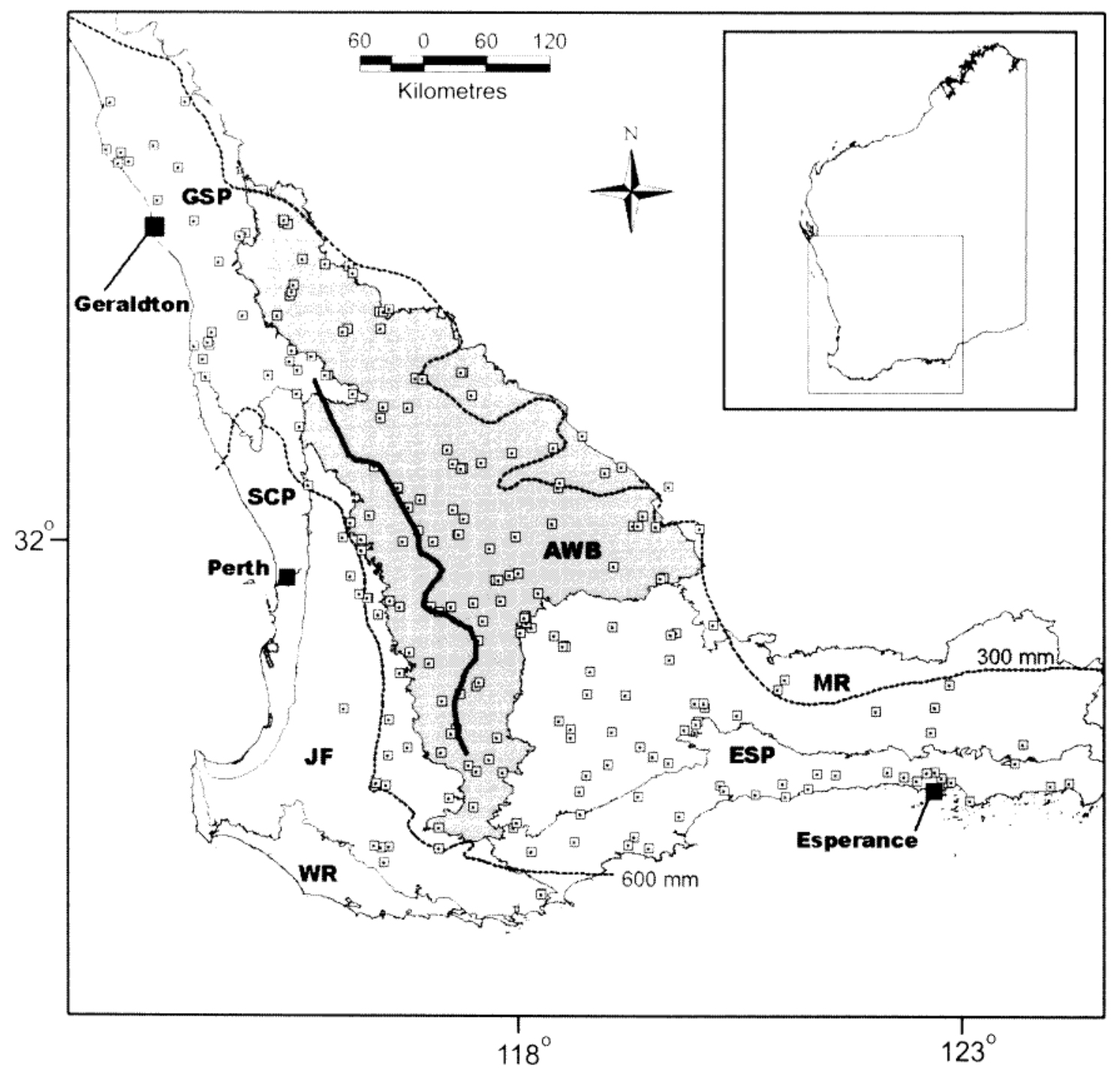

Figure 1 Map of the wheatbelt showing sampling sites (@), IBRA bioregions, rainfall isohyets and the Meckering Line (bold line). AWB, Avon-Wheatbelt; ESP, Esperance Sandplains; GSP, Geraldton Sandplains; JF, Jarrah Forest; MR, Mallee Region; SCP, Swan Coastal Plain; WR, Warren Region.

of the valleys (McFarlane et al., 1983). In semi-arid inland regions, aerosol deposition of marine salt has resulted in net accession to underground salt storages over $100 \mathrm{000s}$ of years, so that much of the regional groundwater is saline and additional salt is stored in soil profiles (Clarke et al., 2002). This has occurred because evapotranspiration greatly exceeds rainfall, so most of the salt imported in rainfall is retained in soil profiles rather than exported by the sluggish groundwater drainages.

\section{Land use and dryland salinity}

Within the study area the Avon-Wheatbelt is about $90 \%$ cleared, the Mallee Region $80 \%$, the Geraldton Sandplain $73 \%$ and the Esperance Sandplain 55\% (Shepherd et al., 2001), primarily for dryland cropping and sheep grazing. The Jarrah forest region, though mostly outside of the study area, is about $40 \%$ cleared. Severe hydrological imbalance has resulted from conversion of perennial woodlands and shrublands to annual crops and pastures that use much less water (Clarke et al., 2002). As a consequence, groundwater tables are rising at rates of 0.05 to $1.0 \mathrm{~m}$ per year, with rises exceeding 25 metres in some areas since clearing (George et al., 1995). This has often resulted in both waterlogging and a net export of salt from underground storages: a process commonly referred to as dryland salinity or secondary salinisation. Currently, about $10 \%$ of the Wheatbelt is affected by these processes, but it has been predicted that this could rise to over $30 \%$ without intervention (Clarke et al., 2002; George et al., 1997; Short and McConnell, 2001). The effects of secondary salinisation on aquatic habitats include increased water salinity and altered water chemistry (including a change to almost universal ionic composition), increased streamflow, more prolonged periods of wetland inundation, loss/ changes of vegetation, and formation of new wetlands where water tables intersect the land surface. 


\section{Climate and timing of sampling}

The climate of south-west Western Australia is characterised by mild wet winters and hot dry summers. Average annual rainfall attenuates from the south-west to the north-east, with rainfall declining from $1400 \mathrm{~mm}$ in the far south-west to about $600 \mathrm{~mm}$ along the western edge of the study area to less than $300 \mathrm{~mm}$ further inland. Rainfall is highly seasonal and length of the dry period (rainfall less than evaporation) increases from 2 to 4 months in coastal regions to 7 to 8 months in the interior (Gentilli, 1972). The main temperature gradient is latitudinal, with temperatures increasing northwards rather than from coast to inland.

Sampling was undertaken in late winter or spring between 1997 and 2000 when water depths of wetlands and rivers were likely to be at or near their annual maximum. Wetlands of the central Wheatbelt were mostly sampled in 1997 following near average autumn and winter rainfall (other than some higher rainfall in the eastern central Wheatbelt in late winter/early spring), those of the southern Wheatbelt were mostly sampled in 1998 following average to above average autumn and winter rainfall and northern Wheatbelt wetlands were mostly sampled in 1999 after exceptional rainfall in March and May resulted in very high water levels (and low salinities) for the rest of the year. A few extra wetlands in the central and southern Wheatbelt were sampled in spring 2000 following average to below average autumn and winter rains. Wetlands included in the wetland monitoring project (Cale et al., 2004) were also sampled in spring 1997 to 1999 but not necessarily in the same year as survey sites in the same area.

\section{Site selection}

A total of 223 wetlands were sampled (Appendix 1): 207 during the biological survey project and 16 during the wetland monitoring project. Seven wetlands were sampled in both studies to give 230 sampling events. Survey sites were selected following literature review, field reconnaissance and consultation with other agencies, community groups and landholders, with the aims of including all wetland types present in the Wheatbelt and obtaining a wide geographic coverage of each type. Wetlands for the monitoring project were selected according to criteria specified in Cale et al. (2004) and were sampled every second spring, with one sampling date chosen for each wetland for inclusion in the analyses presented below. Wetlands surveyed included naturally saline playas and coastal lakes, secondarily salinised wetlands, freshwater wetlands such as claypans, swamps, open lakes, granite outcrop pools and artificial wetlands (farm and town water supply reservoirs), rivers, palaeodrainage channels and springs. The location of each site was determined in the field with a hand-held GPS using datum GDA 1984.

\section{Sampling}

On each sampling occasion, two invertebrate samples were collected: one benthic sample using a $250 \mu \mathrm{m}$ mesh net to sample all habitats (including sediments, detritus, submerged vegetation and the water column), and a plankton sample using a 50 $\mu \mathrm{m}$ mesh net to sample the water column and submerged vegetation. Each sample involved sweeping for a total of $50 \mathrm{~m}$ (not usually contiguous) within wadeable depth. The benthic sample was preserved in $70 \%$ alcohol and the plankton sample in buffered formalin (Huys and Boxshall, 1991). Samples were sieved into size fractions and representatives of all taxa were removed from the sample under a dissecting microscope. At each site, $\mathrm{pH}$ and conductivity were measured using a WTW Multiline P4 meter. Water samples were collected approximately $15 \mathrm{~cm}$ below the water surface for laboratory analysis of total dissolved solids (APHA, 1995, method 2540C), turbidity (APHA method 2130B), colour, alkalinity, hardness, concentration of major ions, silica, total filterable persulphate nitrogen and phosphorus and filterable nitrate/nitrite. Samples for nutrient analyses were passed through a filter paper of pore size $0.45 \mu \mathrm{m}$ and frozen in the field, except for highly turbid samples, which were frozen unfiltered and centrifuged prior to analysis. Chlorophyll a,b,c plus phaeophytin a (APHA, 1995) were measured from phytoplankton retained on a glass-filter paper with pore size $45 \mu \mathrm{m}$ after filtering at least $500 \mathrm{ml}$ of water. Concentrations of all chlorophyll fractions were combined for analysis.

For each wetland in the northern Wheatbelt, three sediment cores were taken using a $50 \mathrm{~mm}$ diameter PVC pipe, normally to a depth of 30 to $50 \mathrm{~cm}$. Texture group, sensu Northcote (1971), was determined for all recognizable horizons of one replicate core per wetland and texture for the upper two horizons used in analyses. The upper-most horizons of all three cores were combined and analysed for sediment particle size (\% silt, clay, sand, stones), pH, conductivity, \% gypsum, \% chloride and \% organic content (loss on ignition at $550^{\circ} \mathrm{C}$ ).

\section{Invertebrate identification}

Invertebrates were identified to species level where possible. Morphospecies codes were usually assigned to undescribed species or to species that were represented only by immature stages that could not be associated with described adults. The snail genus Coxiella possibly contains a number of species restricted to south-western Australia but the current taxonomy (MacPherson, 1957) is based on 
suspect morphological characters (Williams and Mellor, 1991) and separation of Coxiclla into species is therefore tentative, as are names used in Appendix 3. Consistency of identification was achieved by the use of a voucher collection, a partial duplicate of which has been lodged with the Western Australian Museum. The identity of most voucher specimens was verified or determined by specialists (see Acknowledgements) with the notable exception of the non-chironomid Diptera. Species codes for some Trichoptera (AV numbers) are those used in Cartwrght (1997), Dean (1999) and St. Clair (2000). Chironomids with ' $V$ ' codes are species previously recognised by D.H.D Edward (The University of Western Australia) and used in publications such as Bunn (1986) and Storey ct al. (1993). Some other chironomid codes are those of Cranston (2000). Pyralidae sp. 39 and Lepidoptera sp. 16 are codes used in Hawking (2001). Species codes for ostracods, copepods and oligochaetes are those used within the Department of Conservation and Land Management and are consistent with Halse, Shiel et al. (2000). While most cladocerans and rotifers have been identified to species level, using Shiel (1995) and literature cited therein, some are only tentatively associated with named species and further work is required to verify these identifications.

\section{Data analysis}

Similarity matrices for species (based on presence/ absence at a site) and wetlands (based on presence/ absence of species) were produced using two-step and Bray-Curtis dissimilarity indices respectively, using PATN v3.5 (Belbin, 1993). Bray-Curtis values greater than 0.9 were re-estimated to provide better resolution of relationships between wetlands with high dissimilarity. Wetlands and species were classified using the agglomerative UPGMA (unweighted pair group arithmetic averaging) routine of PATN, with $\beta$-levels of -0.15 and -0.1 respectively. Wetland groups were delineated by recognising nodes of high dissimilarity. Species assemblages were recognised by visually identifying groups of species with similar patterns of occurrence in a two-way presence/absence table with sites and species ordered according to the above classifications.

Univariate analyses of variance were performed using Statistica v6.1 (Statsoft Inc., 2002) to test for differences in environmental attributes between groups of wetlands from the classification, with post-hoc Neumann-Keuls tests to determine significance of differences between particular groups. Ratios of ions, some of which relate to precipitation branch points, were calculated from ionic concentrations expressed as milliequivalents per litre. Environmental variables were transformed as necessary to achieve homoscedasticity. Pearson correlations were performed to examine inter-relationships between environmental variables.

Wetlands were ordinated in three dimensions using the semi-strong hybrid multidimensional scaling routine in PATN, with 100 iterations, minimum stress differential of 0.005 and 100 random starts. Environmental variables were correlated with orthogonally rotated vector scores from the wetland ordination using the Multiple Linear Regression procedure in Statistica, with transformation of variables where required to approximate normal distribution of residuals. Vector scores for correlated environmental variables were obtained from the PCC routine in PATN and significance of the correlations was tested using 1000 randomisations of the wetland ordination vector scores using the Monte-Carlo (MCAO) routine in PATN.

Relationships between environmental variables and species richness of each assemblage were modelled using generalised linear modelling (poisson regression) in Statistica. Up to 12 uncorrelated environmental variables were selected based on Wald statistics derived from univariate regressions and entered into a best subsets analysis, with competing models of up to 5 variables compared by examining likelihood scores, calculating the adjusted coefficient of deviation $\left(\mathrm{R}^{2}\right)$ (Tabachnik and Fidell, 1983) and examining graphs of observed versus predicted assemblage richness. Highly influential sites were identified using Cook's statistic and sequentially removed and the model re-run until Cook's statistics of remaining cases stabilised. In no cases did this result in change to sign or significance of model parameters, so all sites were retained. Model refinement involved testing interaction terms and transformations of the model variables to improve fit.

\section{Definitions}

Salinity herein refers to total dissolved solids presented as $\mathrm{g} \mathrm{L}^{-1}$. To facilitate discussion we refer to water as being fresh when salinity is $<3 \mathrm{~g} \mathrm{~L}^{-1}$, subsaline when 3 to $10 \mathrm{~g} \mathrm{~L}^{-1}$ and saline when $>10 \mathrm{~g}$ $\mathrm{L}^{-1}$. Species commonly occurring in freshwater but tolerant of some salinity are referred to as halotolerant, while halophiles are those considered to show a strong preference for saline environments.

\section{RESULTS}

\section{Water chemistry}

Water chemistry of Wheatbelt wetlands (Appendix 2) varied considerably. Eighty-six sites were fresh, another 46 were subsaline and the remaining 98 were saline. The freshest sites were 
granite outcrop pools and some of the artificial wetlands (salinity $<0.1 \mathrm{~g} \mathrm{~L}^{1}$ ), while 29 wetlands (mostly large playas) had salinity $>100 \mathrm{~g} \mathrm{~L}^{-1}$ (maximum $328 \mathrm{~g} \mathrm{~L}^{-1}$ ). Wetlands with salinity $>3 \mathrm{~g} \mathrm{~L}^{-1}$ were all $\mathrm{Na}^{+} \mathrm{Cl}^{-}$dominated: normally $\mathrm{Cl}^{-}>\mathrm{SO}_{4}^{2-}$ $>\mathrm{HCO}_{3}$ - (average milli-equivalent percentages 90.2, $8.3: 1.4$ ) and $\mathrm{Na}^{+}>\mathrm{Mg}^{2+}>\mathrm{Ca}^{2+}>\mathrm{K}^{+}$(average percentages $78.5: 15.4: 5.1: 1.0$ ). Seven subsaline wetlands, mostly in the central and southern Wheatbelt, had $\mathrm{HCO}_{3}>\mathrm{SO}_{4}{ }^{2-}$, mostly with $\mathrm{HCO}_{3}$ $\mathrm{SO}_{4}^{2-}<2.5$, but higher (24) at one secondarily saline swamp. Four subsaline to saline wetlands $\left(<25 \mathrm{~g} \mathrm{~L}^{-1}\right)$ in the northern Wheatbelt had $\mathrm{Ca}^{2+}>\mathrm{Mg}^{2+}$, mostly with $\mathrm{Ca}: \mathrm{Mg}<1.5$. One subsaline swamp had $\mathrm{Mg}^{2+}>\mathrm{K}^{+}>\mathrm{Ca}^{2+}$. Using ternery plots of Ca-Mg-Alk and $\mathrm{Ca}-\mathrm{SO}_{4}$-Alk (not shown) we determined that almost all wetlands with salinity $>3 \mathrm{~g} \mathrm{~L}^{-1}$ had ionic composition that would lead to $\mathrm{Na}-\mathrm{Mg}-\mathrm{Cl}-\mathrm{SO}_{4}$ brine via evaporation pathways $1 \mathrm{~B}$ (mostly) or $2 \mathrm{~A}$ (sometimes) sensu Radke et al. (2002). All but two of the $132 \mathrm{~A}$ pathway lakes were essentially freshwater wetlands with mild salinisation $\left(<7 \mathrm{~g} \mathrm{~L}^{-1}\right)$, the exceptions (both with borderline $1 \mathrm{~A} / 2 \mathrm{~B}$ chemistry) being a naturally saline lake in a crater $\left(42 \mathrm{~g} \mathrm{~L}^{-1}\right)$ and a playa (sampled at 30 and $41 \mathrm{~g} \mathrm{~L}^{-1}$ ). Seven salt lakes, including naturally and secondarily saline wetlands ( 3.6 to $120 \mathrm{~g} \mathrm{~L}^{-1}$ ) were of the type to end in $\mathrm{Na}-\mathrm{Mg}-\mathrm{Ca}-\mathrm{Cl}$ brines via pathway $1 \mathrm{~A}$.

All but four of the freshwater wetlands had $\mathrm{Na}^{+}-$ dominated cation composition, with the exceptions having $\mathrm{Ca}^{2+}>\mathrm{Na}^{+}>\mathrm{Mg}^{2+}>\mathrm{K}^{+}$. Cation composition in $\mathrm{Na}$ dominated wetlands was usually $\mathrm{Na}^{+}>\mathrm{Mg}^{2+}>\mathrm{Ca}^{2+}>\mathrm{K}^{+}$but 13 wetlands had $\mathrm{Na}^{+}>\mathrm{Ca}^{2+}>\mathrm{Mg}^{2+}>\mathrm{K}^{+}$and another 13 had $\mathrm{Na}>\mathrm{Mg}^{2+}>\mathrm{K}>\mathrm{Ca}^{2+}$. Most freshwater wetlands were $\mathrm{Cl}$-dominated, either $\mathrm{Cl}>\mathrm{HCO}_{3}>\mathrm{SO}_{4}{ }^{2 \cdot}$ (57 sites) or $\mathrm{Cl}>\mathrm{SO}_{4}{ }^{2}>\mathrm{HCO}_{3} \cdot(17$ sites, mostly granite outcrops, streams and vegetated swamps), but 12 sites, mostly small dams and shallow claypans, had $\mathrm{HCO}_{3}>\mathrm{Cl}^{-}$ $>\mathrm{SO}_{4}{ }^{2-}$.

Most wetlands had circum-neutral to moderately alkaline $\mathrm{pH}$ but a few salt lakes, mostly in the central and southeast, were notably acidic $(\mathrm{pH} 2.1$ to 5.0). These acid salt lakes tended to have high silica concentrations ( $>10 \mathrm{mg} \mathrm{L} \mathrm{L}^{-1}$ ) compared with alkaline salt lakes, though many freshwater wetlands had even higher concentrations. Some of the shallow freshwater claypans, plus two deeper lakes along the north coast had turbidity $>1000$ NTU, and some of the shallow saline playas with clay sediments had turbidity 250 to 1200 NTU (presumably owing to suspension of sediments by wave action).

Significant correlations, with $\mathrm{R}^{2}>0.5$, were found between several climate and geographic variables and between various ionic composition and related variables, for example salinity was strongly correlated with hardness $\left(\mathrm{R}^{2}=0.84\right)$ and turbidity was correlated with concentration of silica $\left(R^{2}=0.69\right)$.

\section{Aquatic invertebrate diversity}

At least 957 taxa were collected from wetlands during the biological survey and wetland monitoring projects (Appendix 3). Species richness at a site varied from 0 (at the highly saline and acidic Lake Gounter, SPS020) to 107 (Arro Swamp, SPS183) and averaged $40.1 \pm 1.6$ per wetland. Approximately half of the taxa were identified as formally described species, with most of the rest assigned species codes. Microinvertebrates (protozoans, rotifers, cladocerans, ostracods and copepods) constituted about half of the fauna while most of the remainder were insects. Groups with most species were rotifers (18\% of total richness), cladocerans $(12 \%)$, ostracods $(10 \%)$, copepods $(8 \%)$, dipterans (18\%, mostly chironomids), beetles ( $9 \%$, half dytiscids), annelids (4\%) and water mites (3\%). Testate protozoans listed in Appendix 3 were bycatch of a sampling program designed to collect multicellular animals and are a small fraction of the protozoan fauna that would be collected using appropriate techniques.

About $10 \%$ of species were confirmed as undescribed and recognised for the first time in this study. Most of these were rotifers, particularly Lecanidae (Segers and Shiel, 2003), ostracods (Halse and McRae, 2004) and cladocerans. The latter include a proliferation of chydorids, a group which has radiated in the south-west of Western Australia (Frey, 1991,1998). There were also new oligochaetes (e.g. Pinder and Halse, 2001), a leech (possibly a new genus of Hirudinidae), a Manayunkia polychaete, two snails (Glacidorbis and Bithynia), at least one conchostracan (Caenestheriella), many copepods including Calamoecia trilobata (Halse and McRae, 2001), a brine shrimp (Parartemia), two Branchinella fairy shrimps (Timms, 2002) and several beetles, including Antiporus mcraeae and Antiporus pennifoldae (Watts and Pinder, 2000) and new species of Paroster. In addition, some of the chironomids are undoubtedly larvae of undescribed species.

Another $7 \%$ of taxa were recorded in Western Australia for the first time. Most of these were rotifers (40 species and 10 genera, with Notholca salina and Plationus polyacanthoides new to Australia) or cladocerans (21 species), reflecting the paucity of study of smaller microfauna in Western Australia. Austrotrombella n. sp., from two streams in the north of the study area, plus subsequent unpublished records from nearby mound springs, represent the only records of this water mite genus outside southeastern South Australia. The polychaete Manayunkia n. sp., from south coast lakes and two inland sites, is the only polychaete recorded from inland playas, as opposed to coastal salt lakes. Its only Australian congener inhabits coastal salt lakes of South Australia's Coorong region (De Deckker and Geddes, 1980). The jellyfish collected from one 


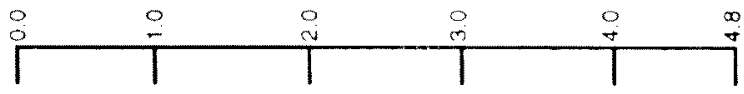

WG1

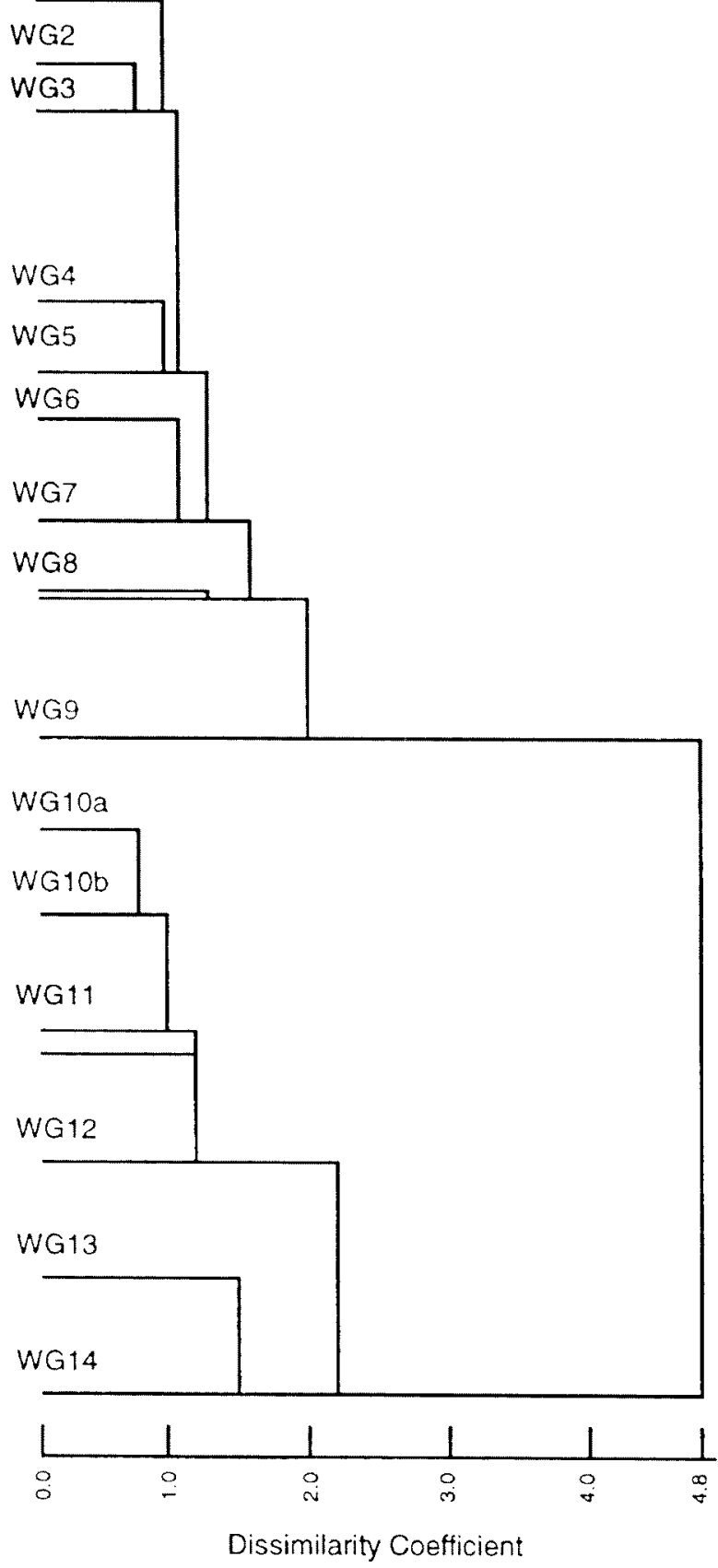

Figure 2 Classification of wetlands by unweighted pair group arithmetic averaging based on BrayCurtis dissimilarity of community composition, showing wetland groups WGI to WGI4

south coast river was tentatively identified as Australomedusa baylit (of the monospecific Australomedusidae), which is otherwise known only from salt lakes of the Beachport-Robe region of South Australia. First Western Australian records of hygrobiid beetles (larvae from two swamps in the south-west of the study area) prompted Hendrich (2001b) to undertake further fieldwork and publish the new species Hygrobia wattsi. Several species, such as the beetles Hydrochus lateviridus and Laccophilus sharpi and the dragonfly Austrogomphus gordoni were known from northern or inland Western Australia, but had not previously been collected in the south-west.

\section{Invertebrate assemblages}

Classification of species according to their patterns of co-occurrence was based on a matrix of 549 species by 202 wetlands, after exclusion of singleton species and sites, artificial wetlands, protozoans and a number of taxa (such as nematodes) that were considered likely to represent multiple species. This classification (shown as a simplified dendrogram in Figure 2 and fully in Appendix 4) was combined with a classification of sites according to community composition (detailed below) to produce a two-way table from which 10 assemblages of species with similar patterns of occurrence were recognised. Figure 3 presents an index $\left(f_{i}\right)$ of fidelity of assemblages to site groups derived from the equation in Boesch (1977) scaled to values between 0 (absence of an assemblage in a site group) and 1 (complete fidelity). To investigate preferred habitats of these assemblages, generalised linear modelling was used to relate species richness of an assemblage at a wetland to its environmental attributes. Models are presented in Table 1 with associated $R^{2}$ values. Wald statistics were significant (mostly $P<0.001$ ) for all parameters and variance inflation factors were all below 3.0, indicating there was little auto-correlation among predictor variables. The assemblages were:

Assemblage A: A large assemblage of 148 species, mostly collected in freshwater swamps in the Jarrah Forest and Esperance Sandplains bioregions. The generally south-western distributions of assemblage A species were typified by common species such as the copepod Calamoecia attenuata, Perthia amphipods and the beetle Uvarus pictipes, though most species of the assemblage were collected infrequently. Rotifers and cladocerans were particularly well represented. Many assemblage A species have been widely collected in the wetter south-west previously and the assemblage appears to be a mesic-adapted fauna for which the inland and northern Wheatbelt, characterised by more seasonally variable water chemistry and hydrology, probably represents sub-optimal habitat. Notable exceptions were three subgroups of 10 to 13 species, each of which were more widespread but sparsely distributed and co-occurred at one of three more inland or northern sites (Lake Cronin, SPSO03; Arro Swamp, SPS183; Punjewerry Claypan, SPS197). These seemingly mis-classified species were in fact 
Table 1 Models relating richness of aquatic invertebrate assemblages to environmental parameters. Variables are latitude in decimal degrees (LAT); longitude in decimal degrees (LON); elevation above sea level (m) (ELE); coefficient of variation of precipitation (COV); precipitation $(\mathrm{mm})$ during the driest quarter (PDQ); mean annual precipitation (mm) (APM); total dissolved solids ( $\left.\mathrm{g} \mathrm{L}^{-1}\right)$ (TDS); categorical TDS quartiles 1,2 and 3 (TDS1,2,3); alkalinity $\left(\mathrm{mg} \mathrm{L}^{-1}\right)(\mathrm{ALK})$; chlorophyll concentration $\left(\mathrm{mg} \mathrm{L}^{-1}\right)(\mathrm{CHL})$; \% bicarbonate $\left(\% \mathrm{HCO}_{3}\right)$; presence/absence of flow (FLO), habitat is pools on granite outcrops (GRA).

\begin{tabular}{|c|c|c|c|}
\hline Assemblage & Ln richness $=$ & Standard Errors & Adjusted $R^{2}$ \\
\hline $\mathbf{A}$ & $\begin{array}{l}-7.2012+0.0037 \mathrm{AMP}+0.2279 \mathrm{LAT}- \\
0.1113 \mathrm{TDS}-0.0052 \mathrm{ALK}\end{array}$ & $\begin{array}{l}\text { constant } 1.0018 \text {, AMP } 0.0003 \text {, LAT } 0.0327 \text {, } \\
\text { TDS } 0.0148 \text {, ALK } 0.0008\end{array}$ & 75 \\
\hline B & $-1.3813+3.7167 \mathrm{GRA}$ & constant 0.1414, GRA 0.1754 & 62 \\
\hline $\mathrm{C}$ & $\begin{array}{l}-53.4344+0.1612 \mathrm{LON}-0.5429 \mathrm{TDS}+ \\
0.9960 \log _{10}(\mathrm{TDS})+8.3222 \mathrm{pH}- \\
0.4806 \mathrm{pH}^{2}+1.2101 \mathrm{FLOW}\end{array}$ & $\begin{array}{l}\text { constant } 11.186, \text { LON } 0.047 \text {, TDS } 0.096 \\
\log _{10} \text { TDS } 0.333, \mathrm{pH} 2.435, \mathrm{pH}^{2} 0.149 \\
\text { FLO } 0.255\end{array}$ & 58 \\
\hline D & $\begin{array}{l}3.6716-0.1021 \mathrm{LAT}-0.0574 \mathrm{TDS}+ \\
0.1821 \ln (\mathrm{TDS})+0.0053 \mathrm{CHL}\end{array}$ & $\begin{array}{l}\text { constant } 1.136, \text { LAT } 0.036, \text { TDS } 0.010 \\
\text { LnTDS } 0.060, \text { CHL } 0.001\end{array}$ & $\begin{array}{l}36 \text { (full model) } \\
29 \text { (TDS only) }\end{array}$ \\
\hline $\mathbf{E}$ & $\begin{array}{l}3.722-0.0013 \mathrm{AMP}-0.0412 \mathrm{TDS}+ \\
0.000095 \mathrm{TDS} 2\end{array}$ & $\begin{array}{l}\text { constant } 0.0723 \text {, AMP } 0.0002, \text { TDS } 0.0017 \text {, } \\
\text { TDS }^{2} 0.000008\end{array}$ & $\begin{array}{l}70 \text { (full model) } \\
67 \text { (without AMP) }\end{array}$ \\
\hline $\mathbf{F}$ & $\begin{array}{l}12.2623+0.1487 \mathrm{LAT}-0.1279 \mathrm{LON}+ \\
0.0011 \mathrm{AMP}-0.1469 \mathrm{TDS}\end{array}$ & $\begin{array}{l}\text { constant } 2.5437 \text {, LAT } 0.0278 \text {, LON } 0.0263 \text {, } \\
\text { AMP } 0.0003 \text {, TDS } 0.0098\end{array}$ & 79 \\
\hline G & $\begin{array}{l}0.5900-0.176 \mathrm{PCV}+0.0246 \mathrm{TDS}- \\
0.0001 \mathrm{TDS}^{2}-0.2283 \% \mathrm{HCO}_{3}\end{array}$ & $\begin{array}{l}\text { constant } 0.3631, \mathrm{PCV} 0.0052, \mathrm{TDS} 0.0038 \\
\mathrm{TDS}^{2} 0.00002, \% \mathrm{HCO}_{3} 0.0659\end{array}$ & $\begin{array}{l}58 \text { (full model }) \\
42\left(\% \mathrm{HCO}_{3} \text { only }\right)\end{array}$ \\
\hline $\mathbf{H}$ & $\begin{array}{l}-0.8020-2.3429 \text { TDS1 }+0.6945 \text { TDS3 }+ \\
0.2467 \mathrm{pH}\end{array}$ & $\begin{array}{l}\text { constant } 0.2873 \text {, TDS1 } 0.2645 \text {, TDS3 } 0.0828 \text {, } \\
\text { pH } 0.0344\end{array}$ & 60 \\
\hline $\mathbf{I}$ & $\begin{array}{l}-16.2639+2.1168 \text { FLOW + 0.4281LAT }- \\
0.0045 \mathrm{ELEV}+2.2038 \mathrm{TDS} 2+2.4538 \mathrm{TDS} 3\end{array}$ & $\begin{array}{l}\text { constant } 2.4536 \text {, FLO } 0.2067 \text {, LAT } 0.0715 \text {, } \\
\text { ELE } 0.0010, \text { TDS2 } 0.5284 \text {, TDS3 } 0.5369\end{array}$ & 66 \\
\hline$J$ & $\begin{array}{l}-2.4147+2.5623 \text { FLOW }+0.0039 \text { AMP }- \\
0.0180 \mathrm{PDQ}-2.6078 \mathrm{TDS} 3-2.5994 \mathrm{TDS} 4\end{array}$ & $\begin{array}{l}\text { constant } 0.4711, \text { FLOW } 0.2479, \text { AMP } 0.0009 \\
\text { PDQ } 0.0064, \text { TDS3 } 0.7290, \text { TDS4 } 1.0228\end{array}$ & 69 \\
\hline
\end{tabular}

no more common in the higher rainfall south-west than elsewhere and further collection would probably reveal distributions more like those of assemblages $\mathrm{D}$ and $\mathrm{E}$ below. High richness of assemblage $A$ was associated with high precipitation, low salinity and low alkalinity (Table 1).
Assemblage B: Thirty-three species most likely to be found in, or even restricted to, pools on granite outcrops, though some were also common in shallow claypans, suggesting a general affinity for ephemeral freshwater. Most species occurred infrequently, even on granite outcrops. Cladocerans, ostracods and conchostracans were

\section{Wetland Group}

WG1 WG2 WG3 WG4 WG5 WG6 WG7 WG8 WG9 WG10 WG11 WG12 WG13 WG14

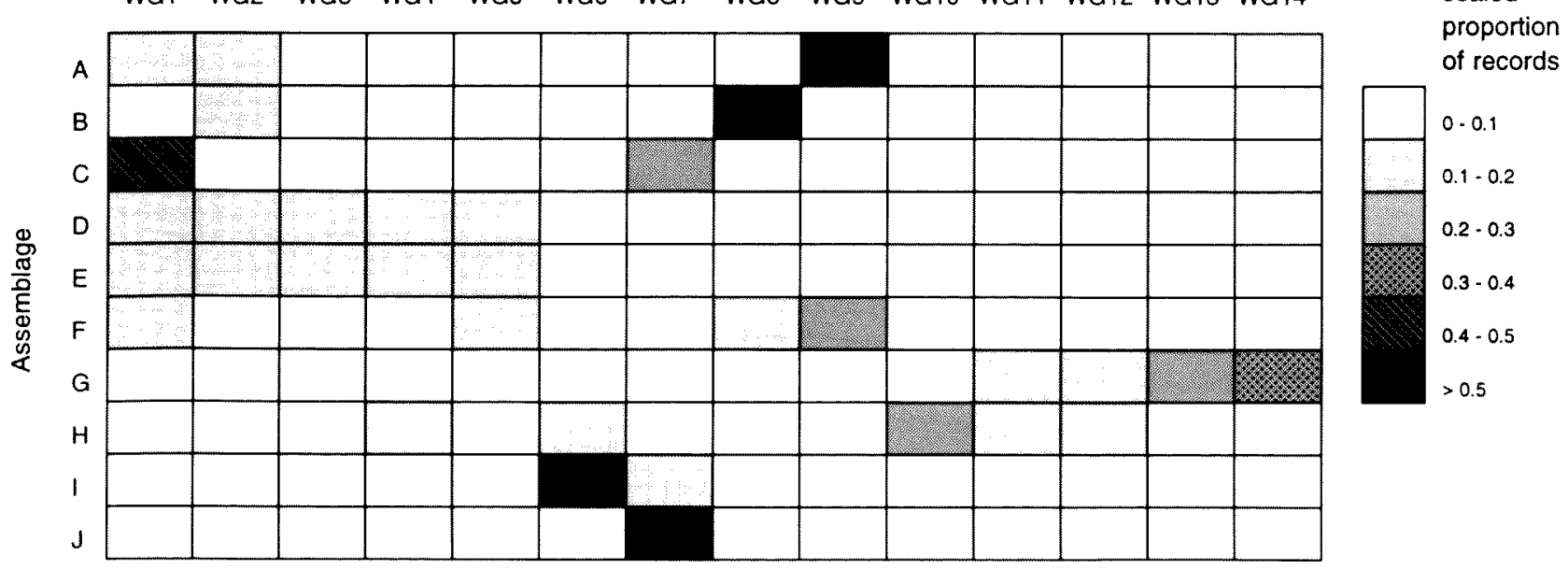

Figure 3 Two-way table showing fidelity $\left(f_{i j}\right)$ (sensu Boesch, 1977) of assemblages to wetland groups. Numbers in brackets are numbers of sites in groups or species in assemblages. 
comparatively well represented in this assemblage and several of them, including Marothrix hardinsi, Daphnia jollyi and Boeckella opaqua were already known to be closely associated with granite outcrop pools. Several singleton species, excluded from analysis, are also known or suspected to be strongly associated with granite outcrop pools, including Acdes occidentalis, Branchinella longirostris and new species such as Asplanchnopus n. sp., Celsinotum n. sp. and several ostracods (Pinder et al, 2000). Daphnia jollyi, previously known only from granite pools, was collected from two other freshwater habitats (a Melaleuca swamp in the northern Wheatbelt and a shallow open lake near the southcoast) showing that the association with granite outcrop pools may not be as rigid as assumed for some species. Species common in claypans were Branchinella affinis, Caenestheriella n. sp. and Berosus nutans.

Assemblage C: A suite of 19 species that showed a strong preference for freshwater swamps and lakes of the more inland and northern parts of the Wheatbelt and, for some species, rivers flowing to the west coast. Most of the species are widely distributed in southern Australia and occur on the Swan Coastal Plain (Davis et al., 1993) and/or in the Carnarvon Basin (Halse, Shiel et al., 2000). Richness was weakly predicted by the presence of flow, high longitude, low salinity and circum-neutral $\mathrm{pH}$ (the $\mathrm{pH}^{2}$ term indicating lower richness in more alkaline water) (Table 1).

Assemblage D: A group of 56 mostly halotolerant species that were collected infrequently but occurred in a wide range of fresh to subsaline wetlands across the Wheatbelt, rarely occurring in more saline waters. Many of the species have pansouthern distributions, though some are known to date only from the Wheatbelt. Rotifers, copepods and cladocerans were disproportionately well represented in assemblage $D$ but chironomid midges and dytiscid beetles were underrepresented. Richness was related to low latitude, high chlorophyll and low salinity (Table 1), but the model had low predictive power, probably related to the sparse occurrence of the species and their distribution beyond the study area. Salinity was the parameter accounting for most variation in assemblage richness.

Assemblage E: These 91 widespread species occurred across the same broad range of fresh to subsaline wetlands as assemblage $D$ but were collected more frequently. In contrast to assemblage D, taxonomic composition was biased towards insects rather than microinvertebrates. A small subgroup of well-known halotolerant species, including the midges Tanytarsus fuscithorax and Procladius paludicola, the amphipod Austrochiltonia subtenuis, the beetle Necterosoma penicillatus and the damselfly Austrolestes amulosus were particularly eurytolerant with respect to salinity (e.g. up to $77 \mathrm{~g} \mathrm{~L}^{-1}$ for $A$. subtenuts) but most assemblage $D$ species were restricted to salinities of $\leq 10 \mathrm{~g} \mathrm{~L}^{-1}$. High richness of the assemblage was strongly associated with low salinity and there was a weak but significant association with low latitude (Table 1)

Assemblage F: A group of 83 species most frequently collected in fresh to mildly subsaline $<5$ $\left.\mathrm{g} \mathrm{L}^{-1}\right)$ lentic wetlands and rivers. A disproportionate number of these species were rotifers whereas dipterans (other than chironomids) were underrepresented. As for assemblage $A$, high richness was associated with freshwater in more coastal or south-westerly high rainfall regions but individual species of assemblage $F$ occurred more widely across the study area than those of assemblage A.

Assemblage $\mathrm{G}$ : The 38 species in this assemblage, mostly ostracods, brine shrimp, copepods and dipterans, showed a strong preference for naturally saline wetlands with moderate to high salinity (maximum richness at salinities 30 to $150 \mathrm{~g} \mathrm{~L}^{-1}$ ). Half of the species were undescribed or were unidentified dipteran larvae, showing that much remains unknown about salt lake invertebrates. Most assemblage members, such as Diacypris ostracods, were widespread but some of the Parartemia species showed restricted distributions that matched boundaries observed during the doctoral studies of A. Savage (The University of Western Australia, pers. comm.). Whatever their geographic distribution, most species were collected infrequently and very few were collected in secondarily saline wetlands. Species of assemblage $G$ seem to tolerate wide ranges of salinity, e.g. the commonly occurring copepod Meridiecyclops baylyi was collected in an inland secondarily saline wetland of $20 \mathrm{~g} \mathrm{~L}^{-1}$ but also at 180 $\mathrm{g} \mathrm{L}^{-1}$ in the coastal, naturally saline Hutt Lagoon and the ostracod Australocypris bennetti was collected in waters of salinity 33 to $240 \mathrm{~g} \mathrm{~L}^{-1}$. A small number of species showed a strong preference for highly acidic salt lakes: the copepod Calamoecia trilobata ( $\mathrm{pH} 3.0$ to 6.3), brine shrimp Parartemia contracta (2.4 to 4.2) and ostracods Reticypris sp. 556 (3.0 to 4.0) and Diacypris sp. 523 (twice at 3.8). Other species sometimes occurred at low pH but most were absent from the acidic sites. Richness of assemblage $G$ was weakly predicted by highly seasonal rainfall, high salinity and low $\% \mathrm{HCO}_{3}{ }^{-}$(Table 1). The latter variable was the strongest model parameter when considered alone, but did not add much to a model already including rainfall variability and salinity. Low $\% \mathrm{HCO}_{3}$ seems to indicate the presence of moderate to high salinity (when $\% \mathrm{HCO}_{3}^{-}$is negligible in Western Australian water) rather than being of direct biological relevance by itself.

Assemblage $\mathbf{H}$ : Twenty-five species, half of which were ostracods or dipterans, that showed a strong affinity for subsaline to moderately saline 
waters, including saline streams of the south coast, though a few occurred occasionally in freshwater. These species were less likely to avoid secondary salinity than members of assemblage G. Most are widespread in the south-west and southern Australia, with the exception of two Coxiella snails that may be endemic. Inclusion of salinity quartiles 1 and 3 in the model reflected the non-linear response of richness to salinity, with peak richness of this assemblage in the 5 to $50 \mathrm{~g} \mathrm{~L}^{-1}$ range. Inclusion of $\mathrm{pH}$ reflected particularly high richness in more alkaline wetlands within the above salinity range.

Assemblage I: A group of 22 species most frequently collected in saline streams flowing to the south coast but also found occasionally in saline lentic wetlands located either near the coast or with some hydrological connection to saline streams. Copepods and macrocrustaceans were particularly well-represented in this assemblage, most members of which are widely distributed in southern Australia. A number of species, including Capitella polychaetes, the snail Ascorhis occidua and amphipod Melita kauerti primarily inhabit estuarine or coastal habitats but were found to extend well upstream in saline rivers and to occur in some associated lentic wetlands. Also included was a southern Australian caddisfly, Symphitoneuria wheeleri, which has an affinity for saline waters. Richness in this assemblage was associated with the presence of flow, southerly latitudes, coastal situations (indicated by low elevation) and moderate salinity (Table 1).

Assemblage J: Thirty-four species that occurred in fresh to subsaline streams in catchments draining to the west coast, but rarely in more saline streams or lentic wetlands. High richness of this insectdominated assemblage was associated with the presence of flow, high annual precipitation, low precipitation during the driest quarter and low salinity (Table 1). The association with the climate variables is related to the generally north-western locations of the low salinity rivers sampled in this survey.

\section{Wetland classification}

Fourteen groups of wetlands (WG1 to WG14) were identified from the classification of wetlands according to the composition of their aquatic invertebrate communities (Figure 2, Appendix 4). The geographical distribution of sites within each group is shown in Figure 4 while Table 2 summarises species richness, fidelity of species to wetland community groups and occurrence of singleton species. Box-plots of selected environmental variables by wetland group are presented in Figure 5. Analyses of variance indicated that all environmental variables (except for chlorophyll) differed significantly between the wetland groups (mostly with $P<0.001)$. To further investigate the contribution of particular wetland groups to these differences, Neumann-Keuls post-hoc tests were performed and results of these are discussed in relation to wetland groups below.

The major division in the dendrogram was between 117 wetlands (WG1 to WG9) with speciesrich communities dominated by assemblages $\mathrm{A}$ to $\mathrm{F}$ (plus I and J in rivers) and 85 wetlands (WG10 to WG14) with depauperate communities dominated by assemblages $G$ and $H$. The former groups were mostly composed of fresh to subsaline wetlands (3.7 $\pm 0.4,0.03$ to $\left.21 \mathrm{~g} \mathrm{~L}^{-1}\right)$ whereas wetlands of WG10 to WG14 were mostly saline $\left(71.7 \pm 6.6,3.4-300 \mathrm{~g} \mathrm{~L}^{-1}\right)$, with most of the overlap in salinities occurring in the 10 to $20 \mathrm{~g} \mathrm{~L}^{-1}$ range. Five of the wetlands in the higher salinity part of the dendrogram were subsaline ( 3.4 to $8.4 \mathrm{~g} \mathrm{~L}^{-1}$ ) when sampled but four of these were more saline (13 to $25 \mathrm{~g} \mathrm{~L}^{-1}$ ) about six weeks prior to sampling. Communities in those four wetlands reflected the earlier salinity (species poor, with Haloniscus searlei and Australocypris insularis present but numerous species normally associated with low salinity conditions absent, such as Polypedilum nubifer, Sarscypridopsis aculeata and Anisops thienemanni). This seems to account for the occurrence of these subsaline wetlands in the more saline part of the classification. Similar reductions in salinity (owing to localised rainfall events) did not occur for subsaline wetlands of the freshsubsaline part of the classification. Four sites, which either formed a small group by themselves (SPS179, SPS186 and SPS076) or which mis-classified with obviously dissimilar wetlands, apparently on the basis of low richness (SPS087), were excluded from analyses of variance.

WG1: Species-rich freshwater wetlands. Twentythree mostly freshwater lentic wetlands located primarily in the southern Avon-Wheatbelt and Mallee regions, plus a few northern and southeastern coastal sites. These were a diverse array of lakes varying in level of disturbance, vegetation type and cover, basin morphology, depth, water chemistry and sediments. Communities in these wetlands were distinguished from those of other freshwater and subsaline wetlands by high richness of assemblages C, E and F, with the first-mentioned having moderate fidelity to WG1. Communities of three widely separated wetlands (Lake Cronin, SPS003; Arro Swamp, SPS183; Qualeup Lake, SPS032) included particular subsets of 10 to 13 species from assemblage $\mathrm{A}$, but this assemblage was otherwise poorly represented in wetlands of WG1. Total richness in these sites was higher than in other groups of freshwater wetlands, except for the southern swamps (WG 9).

The next two groups of freshwater wetlands had faunas that were essentially depauperate versions 

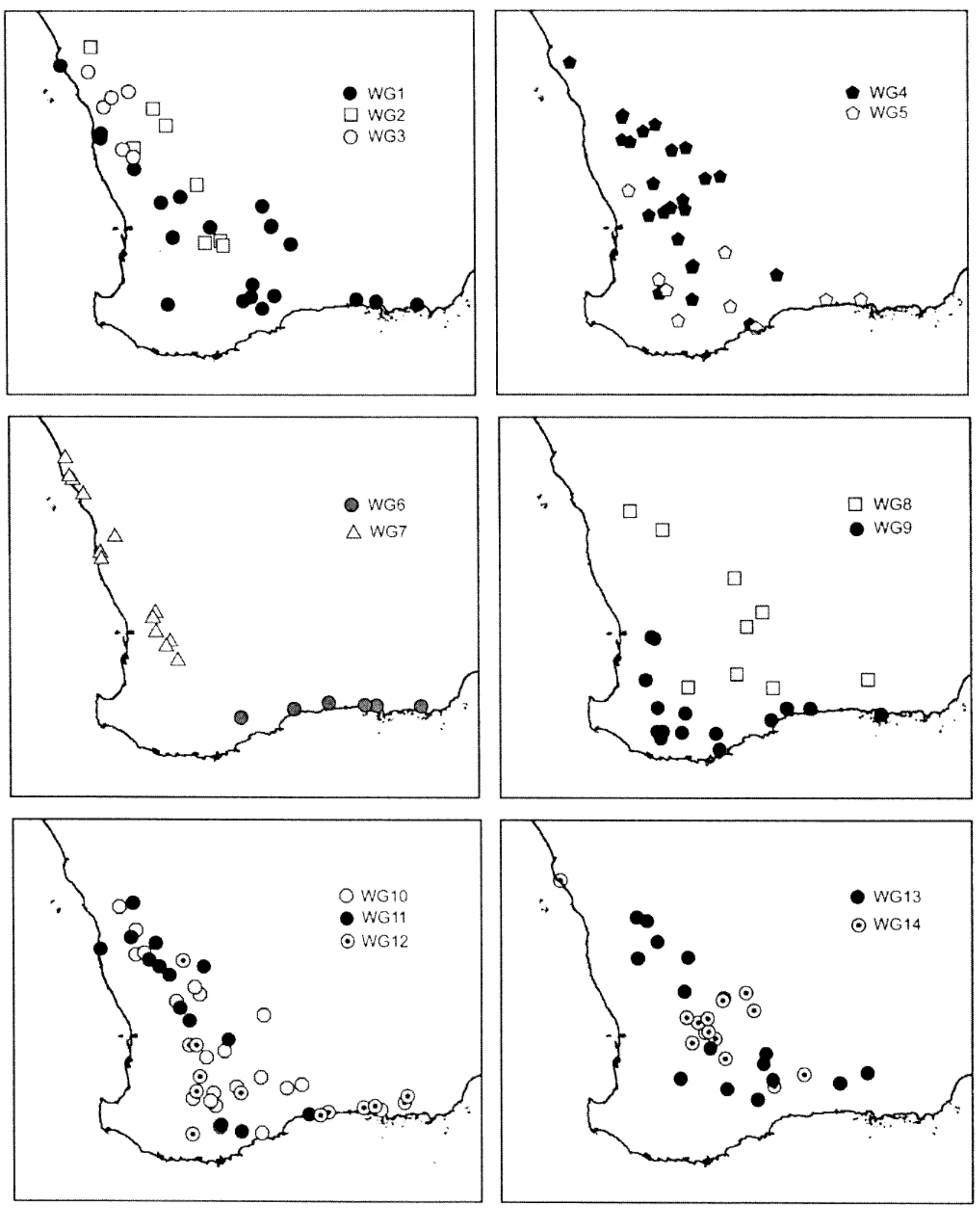

Figure 4 Maps of the wheatbelt showing location of wetlands by wetland group.

of those in WG1, with much lower richness of assemblages $\mathrm{C}$ and $\mathrm{F}$ in particular.

WG2: Claypans. These eight shallow alkaline claypans (depth $<30 \mathrm{~cm}$, pH $8.6 \pm 0.35$ ) were located in the Avon-Wheatbelt and inland parts of the Geraldton Sandplains, though wetlands of similar appearance in parts of the Mallee bioregion might have supported similar communities had they held water when visited. Turbidity, while low in some sites when sampled, was significantly higher ( $P$ $<0.001$ ) in this group than in other site groups and all sites had clayey sediments. These claypans also had significantly more phosphorus than most site groups (usually $P<0.01$ ). Numerous species that 

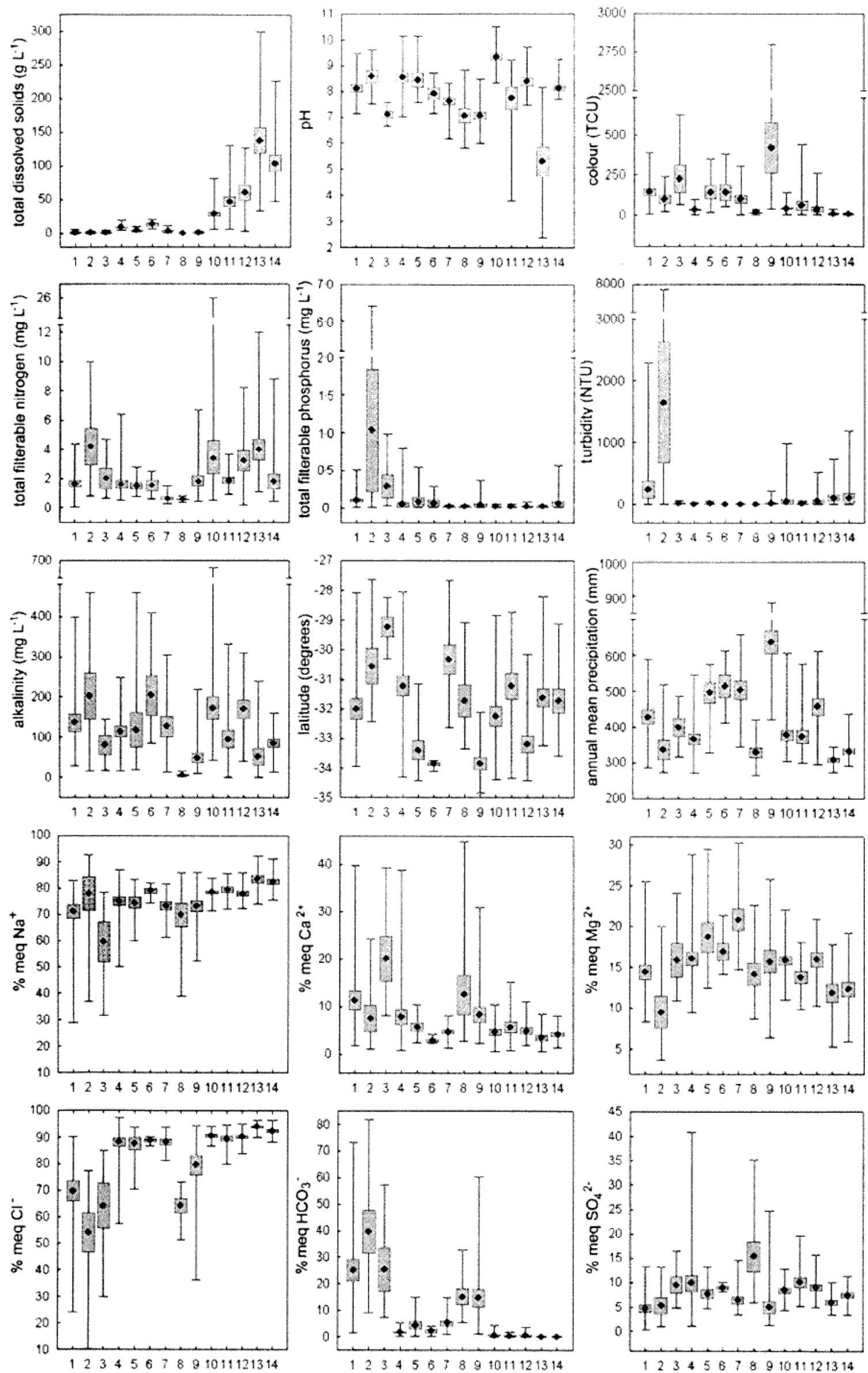

Figure 5 Box plots of selected environmental variables (with mean, standard error and minimum and maximum represented by the point, box and bars respectively) for each of the 14 wetland groups. 
were otherwise common and widespread in freshwater, such as the amphipod Austrochiltonia subtenuis and several chironomids, mosquitoes, beetles and dragonflies tended to be absent from claypans. Conversely, several species from various assemblages were common in claypans but rare to absent elsewhere, including the fairy shrimp Branchinella affinis, a midge Paracladopelma sp. A, Isidorella snails and conchostracans belonging to Caenestheriella and Lynceus. Site group WG1 also included some very turbid wetlands but these were deeper ( $>1.5$ metres) and did not contain the claypan species.

WG3: Northern tree swamps. Six freshwater wetlands dominated by trees or (for one site) trees and samphire, located inland on the Geraldton Sandplains and the northern extent of the AvonWheatbelt. This group of wetlands were less alkaline $(P<0.01)(\mathrm{pH} 7.1 \pm 0.4)$ and had sandier sediments than the claypans and higher (mostly $P$ $<0.01$ ) phosphorus concentrations than other site groups, except for WG1 and WG2. The contribution of calcium to cation concentration was higher, and contribution of sodium lower, in these swamps than wetlands of other site groups $(P<0.05$ to $<0.001$ ). There was some complementarity in the fauna of the northern tree swamps and claypans, with swamps lacking some species typical of claypans but containing some species notably absent from claypans. Otherwise communities of WG3 wetlands were simply depauperate versions of those present in wetlands of WG1, except that Culex australicus mosquitoes were notably common in these wetlands.

WG4 and WG5: Subsaline wetlands. The majority of subsaline lentic wetlands formed two sister groups in the dendrogram, with wetlands of WG4 having higher salinity $\left(8.6 \pm 0.8 \mathrm{~g} \mathrm{~L}^{-1}\right)$ than those of WG5 $\left(4.0 \pm 0.8 \mathrm{~g} \mathrm{~L}^{-1}\right)(P<0.05)$. These groups included some naturally saline samphire pans and healthy Melaleuca cuticularis swamps but most showed signs of mild to severe secondary salinisation. Communities in wetlands from both groups were characterised by frequent occurrence of both halophiles (of assemblage $\mathrm{H}$ ) and halotolerant species (of assemblages D and E) but low richness of those assemblages that appear to have least tolerance of salinity (A, C and F). These groups of subsaline wetlands were distinguished from one another mostly by the relative frequency of occurrence of species from assemblages D, E and F (e.g. the dragonfly Hemianax papuensis and caddisfly Triplectides australis present in most WG4 sites but few or no WG5 sites, and vice versa for the water mite Acercella falcipes and ostracod Alboa wooroa). The only species restricted to wetlands of WG4 and WG5 were singletons in the data set. The more limited geographic distribution of WG5 wetlands (Figure 4) probably reflects a sampling bias towards lower salinities (within this salinity range) in the southern Wheatbelt, rather than any genuine zoogeographic tendencies of species.

WG6 and WG7: Rivers. Seventeen of the 23 sites with flowing water classified together (Figure 2, Appendix 4). Exceptions were four highly saline channels with low flow within inland palaeodrainage flats (SPS014, 184, 207 and 208), which classified with salt lakes, and 2 sub-saline river pools with substantial backwater habitat (SPS026 and 063) that classified with lentic wetlands. This riverine dominated suite of wetlands was sub-divided into WG6 (four rivers and two lakes, all subsaline to saline and either flowing to, or located near, the south coast) and WG7 (13 fresh to subsaline rivers and springs flowing to the west coast). The south coast sites were less species-rich

Table 2 Summary of species richness by wetland group.

\begin{tabular}{|c|c|c|c|c|c|}
\hline \multirow[b]{2}{*}{$\begin{array}{l}\text { Wetland } \\
\text { group }\end{array}$} & \multirow[b]{2}{*}{$\begin{array}{l}\text { No. } \\
\text { sites }\end{array}$} & \multicolumn{3}{|c|}{ Taxa used in multivariate analyses } & \multirow[b]{2}{*}{$\begin{array}{l}\text { No. } \\
\text { singleton } \\
\text { species }\end{array}$} \\
\hline & & $\begin{array}{l}\text { Total no. } \\
\text { species } \\
\text { from group }\end{array}$ & $\begin{array}{l}\text { Species } \\
\text { restricted } \\
\text { to group }\end{array}$ & $\begin{array}{c}\text { Mean } \\
\text { wetland } \\
\text { richness }\end{array}$ & \\
\hline WG1 & 23 & 297 & 6 & $65 \pm 5$ & 42 \\
\hline WG2 & 8 & 165 & 2 & $46 \pm S$ & 21 \\
\hline WG3 & 6 & 111 & 1 & $46 \pm 7$ & 5 \\
\hline WG4 & 24 & 181 & 4 & $38 \pm 2$ & 15 \\
\hline WG5 & 9 & 174 & 0 & $56 \pm 6$ & 17 \\
\hline WG6 & 6 & 106 & 5 & $36 \pm 3$ & 12 \\
\hline WG7 & 13 & 211 & 16 & $50 \pm 3$ & 46 \\
\hline WG8 & 9 & 159 & 13 & $49 \pm 7$ & 15 \\
\hline WG9 & 18 & 312 & 37 & $71 \pm 5$ & 84 \\
\hline WG10 & 23 & 100 & 2 & $20 \pm 1$ & 4 \\
\hline WG11 & 15 & 95 & 1 & $18 \pm 2$ & 4 \\
\hline WG12 & 14 & 56 & 2 & $13 \pm 2$ & 4 \\
\hline WG13 & 15 & 32 & 3 & $5 \pm 1$ & 5 \\
\hline WG14 & 15 & 44 & 2 & $8 \pm 1$ & 1 \\
\hline
\end{tabular}


than the western sites, but were distinguished by high richness and fidelity of assemblage I, which includes several coastal or estuarine species that are able to penetrate well upstream in saline rivers and have colonised saline wetlands near the coast. By contrast, the western rivers of WG7 were distinguished by particularly high richness and fidelity of assemblage J, with freshwater and halotolerant species from assemblages C, E and F contributing to higher total richness than WG6.

WG8: Pools on granite outcrops. Nine ephemeral pools on nine granite outcrops that had lower salinity than other wetland groups $(P<0.001)$, lower alkalinity $(P<0.01)$ and silica $(P<0.001)$ than other groups of freshwater wetlands and lower phosphorus $(P<0.05$ to $<0.001)$ than all other groups except for westerly flowing rivers (WG7). Also, the contribution of sulphate to anionic composition was higher $(P<0.05$ to $<0.001)$ in these pools than in any other site group, except for the subsaline wetlands of WG4. Pool communities were not especially rich, perhaps because of their small size and relatively simple habitat, but assemblage B showed high fidelity to this habitat. Pinder et al. (2002) concluded that communities in wheatbelt outcrop pools are different from those of similar environments of the more mesic south-west studied by Bayly (1982, 1997). A number of species previously known only from granite outcrops (Pinder et al., 2002) have subsequently been collected from other freshwater habitats during this survey. One claypan, SPS087, mis-classified with the granite sites because of similarly low species richness rather than a shared fauna and its occurrence in WG 8 is discounted.

WG9: Southern swamps. Freshwater swamps in the Jarrah Forest and Esperance Sandplains (Figure 4). Most were dominated by sedges but some had Eucalyptus occidentalis (Swamp Yate) or Melaleuca spp. across the bed. Communities in these swamps had particularly high richness of freshwater assemblages $\mathrm{A}$ and $\mathrm{F}$ (the former showing particularly high fidelity to these swamps) but included fewer halotolerant species (from assemblage E) than other freshwater community types.

The primary division within the more saline part of the classification is between wetlands of WG10 to WG12, with higher richness of halotolerant freshwater species (Assemblage E) and halophiles preferring moderate salinities (Assemblage $\mathrm{H}$ ), and those of WG13 and WG14 with lower richness of these assemblages. The richer wetlands also had more moderate salinity $\left(44 \pm 4,5.4\right.$ to $\left.120 \mathrm{~g} \mathrm{~L}^{-1}\right)$ than the more depauperate wetlands $(124 \pm 12,33$ to 300 $\left.\mathrm{g} \mathrm{L}^{-1}\right)$. In general, structure in this more saline part of the dendrogram tended to reflect the likelihood of occurrence of particular species rather than fidelity of whole assemblages. Other than for salinity and $\mathrm{pH}$, the groups in this portion of the dendrogram were much more uniform with respect to many of the environmental attributes than were the lower salinity groups. All five salt lake groups were dominated by wetlands with $\mathrm{Na}-\mathrm{Mg}-\mathrm{Cl}-\mathrm{SO}_{4}$ (1B) precipitation pathways

WG10: Secondarily saline and degraded naturally saline wetlands. Generally small, moderately saline $\left(28.4 \pm 3.4,5.4\right.$ to $\left.81 \mathrm{~g} \mathrm{~L}^{-1}\right)$ lakes, with samphire, Ruppia and/or dead trees across the lake bed. These wetlands were more alkaline $(P$ $<0.05$ to $<0.001$ ) than other site groups and while most were once fresh and others naturally saline, almost all are now affected by secondary salinity. Compared with communities of other salt lakes, those in WG10 wetlands had higher richness of both halotolerant (Assemblage E) and halophilic (Assemblage $H$ ) species. Species from these assemblages that were more common in WG10 wetlands included the rotifer Hexarthra fennica, ostracod Diacypris spinosa and midge Cladopelma curtivalva. Assemblage $G$ species were also represented in WG10 wetlands but only Meridiecyclops baylyi and Daphniopsis pusilla occurred more than twice: the latter was more common in WG10 sites than in any other wetland group. Two subgroups (10a and 10b) are discernable from the dendrogram. Wetlands in WG10a had higher salinity (19 to $81 \mathrm{~g} \mathrm{~L}^{-1}$ ) and were located in the central and southern Wheatbelt, whereas subgroup $10 \mathrm{~b}$ had lower salinity $(5.4$ to 26 $\left.\mathrm{g} \mathrm{L}^{-1}\right)$ and were mostly located in the central and northern Wheatbelt. The geographic separation of these subgroups is probably artefactual and resulted from sampling the northern Wheatbelt in a particularly wet year when small saline wetlands were more dilute than normal. Moreover, there were only very subtle differences in community composition between the subgroups and they are unlikely to represent robust community types. Composition of communities in any of the wetlands can be expected to flip around within the variability encompassed by the larger group depending on variation in salinity between years. For example, Lake Walymouring fell within 10a when sampled at $81 \mathrm{~g} \mathrm{~L}^{-1}$ during the survey project and within $10 \mathrm{~b}$ when sampled at $25 \mathrm{~g} \mathrm{~L}^{-1}$ in the monitoring project.

WG11: Naturally saline wetlands. A heterogeneous group of naturally saline wetlands including small samphire flats, flowing palaeodrainage flats and large open lakes, some with Ruppia across the bed, mostly located in the central and northern Wheatbelt. Most had higher salinities $\left(46.5 \pm 7.7,6.2\right.$ to $\left.130 \mathrm{~g} \mathrm{~L}^{-1}\right)$ than those of WG10 (although the difference was not significant) and were in good condition although some, such as Anderson's Lake (SPS106), were affected by waterlogging. Richness of assemblages $\mathrm{E}$ and $\mathrm{H}$ was only slightly lower in these communities than in those of WG10 but a greater range of assemblage $G$ 
halophiles were present. Invertebrates particularly likely to occur in WG11 communities were Acdes camptorhynchus, Brachionus plicatilis, Dolichopodidaesp. A and Necterosoma penicillatus.

WG12: Naturally and secondarily saline wetlands. Moderately saline wetlands in the southern Wheatbelt (except for Lake Goorly, a northern outlier) separated into two subgroups according to whether they occurred along the south coast or further inland. Salinity ranged from 20 to $127 \mathrm{~g} \mathrm{~L} \mathrm{~L}^{-1}$ (excluding 2 subsaline sites that were known to have been more saline in the weeks prior to sampling) and averaged $60.3 \pm 7.6 \mathrm{~g} \mathrm{~L}^{1}$, but was not significantly higher than in either WG10 or WG11. Most sites were naturally saline but some of the inland wetlands were affected by secondary salinity. Both subgroups had lower richness of halotolerant and halophile assemblages (E, G and H) than other moderately saline wetlands, but probably for different, albeit unclear, reasons. The copepod Calamoecia clitellata and isopod Haloniscus searlei were collected most frequently in these lakes and the polychaete Manayunkia n. sp. and the snail Coxiella exposita were particularly common in the coastal lakes.

The remaining two groups consist almost entirely of naturally hypersaline ( 50 to $300 \mathrm{~g} \mathrm{~L}^{-1}$ ), strongly seasonal shallow playa lakes with sandy/clayey sediments, little organic matter and virtually no aquatic vegetation. Communities in these wetlands were characterised by very low richness of assemblages $\mathrm{E}$ and $\mathrm{H}$ (halophilic/halotolerant species) but presence of a greater range of halophiles from assemblage $G$ than in the more moderately saline wetlands. Several species (muscid dipteran type A, ostracods Diacypris n. sp., D. whitei and D. fodiens, brine shrimp Parartemia longicaudata and copepod Schizopera sp. 1) were collected only from these highly saline wetlands, although only the muscid and Australocypris bennetti were common in both WG13 and WG14.

WG13: Degraded hypersaline lakes. Mostly playa lakes plus the coastal Hutt Lagoon (SPS189) and Yilgarn River (SPS208, a palaeodrainage channel). All were primarily saline $(137 \pm 19,33$ to $\left.300 \mathrm{~g} \mathrm{~L}^{-1}\right)$ and most had low $\mathrm{pH}(5.14 \pm 0.54,2.39$ to 8.14) and high silica (18.9 $\left.\pm 4.4 \mathrm{mg} \mathrm{L}^{-1}\right)$. Only Baandee Lake (SPS022) had salinity $<100 \mathrm{~g} \mathrm{~L}^{-1}$ and $\mathrm{pH}>6$. While a few were undisturbed (Lake Ronnerup, SPM025; Frank Hahn Salt Lake, SPS089), most are affected by water regulation (Baandee Lake; Ardath Lake, SPM009), secondary salinity (e.g. Yilgarn River; Master's Saline Lake, SPS097), mining activity (Lake in Kondinin Salt Marsh, SPS016; Moorine Lake, SPS099) or have only arisen since clearing (Simpson's Lake, SPS052) and the low $\mathrm{pH}$ of some of these may not be natural. These wetlands appear to have grouped together because they have particularly depauperate faunas (Table 2) rather than because they represent a particular community type. Communities were highly heterogeneous and only the ostracod Australocypris bennetti and Culicoides midges were present at $>50 \%$ of sites. Species showing a strong preference for acidic waters, the brine shrimp Parartemia contractn, ostracod Reticupris sp. 556 and copepod Calamoecia trilobata, were the only other species that were at all common in this group. The ostracod Diacypris sp. 523 was recorded solely from acidic lakes but occurred only twice.

WG14. Hypersaline lakes. Most of these were also naturally saline playas $\left(103 \pm 12,47\right.$ to $\left.226 \mathrm{~g} \mathrm{~L}^{-1}\right)$ but all were alkaline $(8.12 \pm 0.11,7.70-9.22)$, had low silica $\left(1.0 \pm 0.2 \mathrm{mg} \mathrm{L}^{-1}\right)$ and most were relatively undisturbed. As for wetlands of WG13, communities were highly heterogeneous and only 16 of the 44 species occurred more than twice. Five species from assemblage $G$ (the copepod Schizopera sp. 1, brine shrimp Parartemia n. sp. 7 and Parartemia longicaudata, and ostracods Diacypris n. sp. and D. fodiens) were more common in, or even restricted to, these wetlands and assemblage $G$ was richest in, and showed strongest fidelity to, WG14.

\section{Ordinations and multiple correlations}

Ordinations of wetlands based on community composition were performed to investigate discreteness of the wetland groups described above (Figures 6-8). In addition, multiple linear correlations between wetland ordination scores and environmental attributes are presented in Table 3 , with fitted vectors shown for the attributes most highly correlated with each ordination. Figure 6 shows two dimensions of a three-dimensional ordination of all wetlands used in the classification. Two main gradients are apparent from the vectors of environmental attributes in Figure 6a. Firstly, vectors for colour, salinity and a number of ionic composition and ratio variables, such as \% $\mathrm{K}^{+}$, $\% \mathrm{HCO}_{3}$ and $\mathrm{Ca}^{2+}$ :alkalinity, are aligned with the vertical axis. This strong salinity gradient is visible when groups from the cluster analysis are denoted according to the salinity category of their component wetlands (Figure 6b). The vectors for colour and ionic composition indicate a tendency for freshwater wetlands to be more coloured, less $\mathrm{Na}^{+} \mathrm{Cl}$ dominated and to have higher alkalinity than saline wetlands. Secondly, there is a geographic/ climatic gradient, with vectors for latitude, precipitation and spring evaporation aligned with the horizontal axis. This can be seen on Figure 6c, in which the southern and northern-most sites are differentiated. Plots of axes 1 vs 2 and 2 vs 3 are not shown since they simply show the same gradients from different perspectives.

To investigate whether the strong salinity gradient in Figure 6 was masking correlations between other environmental attributes and 
community structure within narrower ranges of salinity, the freshwater lentic wetlands (WG1 to WG3 plus WG8 and WG9) and the saline wetlands (WG10 to WG14) were ordinated separately and new multiple correlations calculated (Table 3).

Figure 7 shows a three-dimensional ordination of wetlands belonging to the five lentic and mostly freshwater groups. This shows clear separation of granite outcrop pools and southern vegetated swamps from each other and from WG1 to WG3 (Figure 7a) but groups within the latter are not well separated from each other (Figure $7 \mathrm{~b}$ ). Most of the salinity and ionic composition variables were less strongly correlated with community composition in this analysis than for the analysis of all wetlands (Table 3). In Figure 7c the vectors for salinity and alkalinity indicate a weak gradient represented at its extremes by very fresh, low alkalinity sites (especially the granite outcrop pools) and a few sites towards the right of the plot with higher alkalinity $\left(>200 \mathrm{mg} \mathrm{L}^{-1}\right)$ and/or salinity (3-6 $\left.\mathrm{g} \mathrm{L}^{-1}\right)$. Nitrogen and phosphorus concentrations, turbidity and $\mathrm{pH}$ were more strongly correlated with community composition in this restricted analysis than in the analysis with all wetlands (Table 3 ) and the direction of their vectors in Figure $7 \mathrm{c}$ reflect the generally lower values of these variables in the granite outcrops (WG8) and southern swamps
(WG9) compared to some wetlands of WG1 to WG3. As for the analysis of all wetlands, there was also a latitudinal/climatic gradient.

In an ordination of saline wetlands, WG10 to WG14 were reasonably well separated, though adjacent, in ordination space (Figure 8a,c). Correlations of community structure with salinity, precipitation, colour and most ionic composition variables were weaker in this analysis than in the analysis of all sites (Table 3), although the correlation coefficient for salinity was still high at 0.72 . Of the ionic composition variables, only alkalinity and related variables and ratios had correlation coefficients $>0.5$, but this seems to be driven largely by low alkalinity in the acidic salt lakes. The $\mathrm{pH}$ vector (Figure $8 \mathrm{~d}$ ) is fairly strong, represented at one extreme by the acidic hypersaline wetlands (mostly WG13) and at the other by the tendency of wetlands with salinity below $50 \mathrm{~g} \mathrm{~L}^{-1}$ (mostly WG10) to be strongly alkaline ( $\mathrm{pH} 8.5$ to 10 ). Most of the sites with high silica concentrations $\left(>20 \mathrm{mg} \mathrm{L}^{-1}\right)$ were acidic salt lakes of WG13 and this is reflected in the direction of the silica vector in Figure 8d. As for freshwater wetlands, there was a geographic/climatic gradient, aligned with ordination axis 3 and largely reflecting the latitudinal separation of WG11 and WG12.

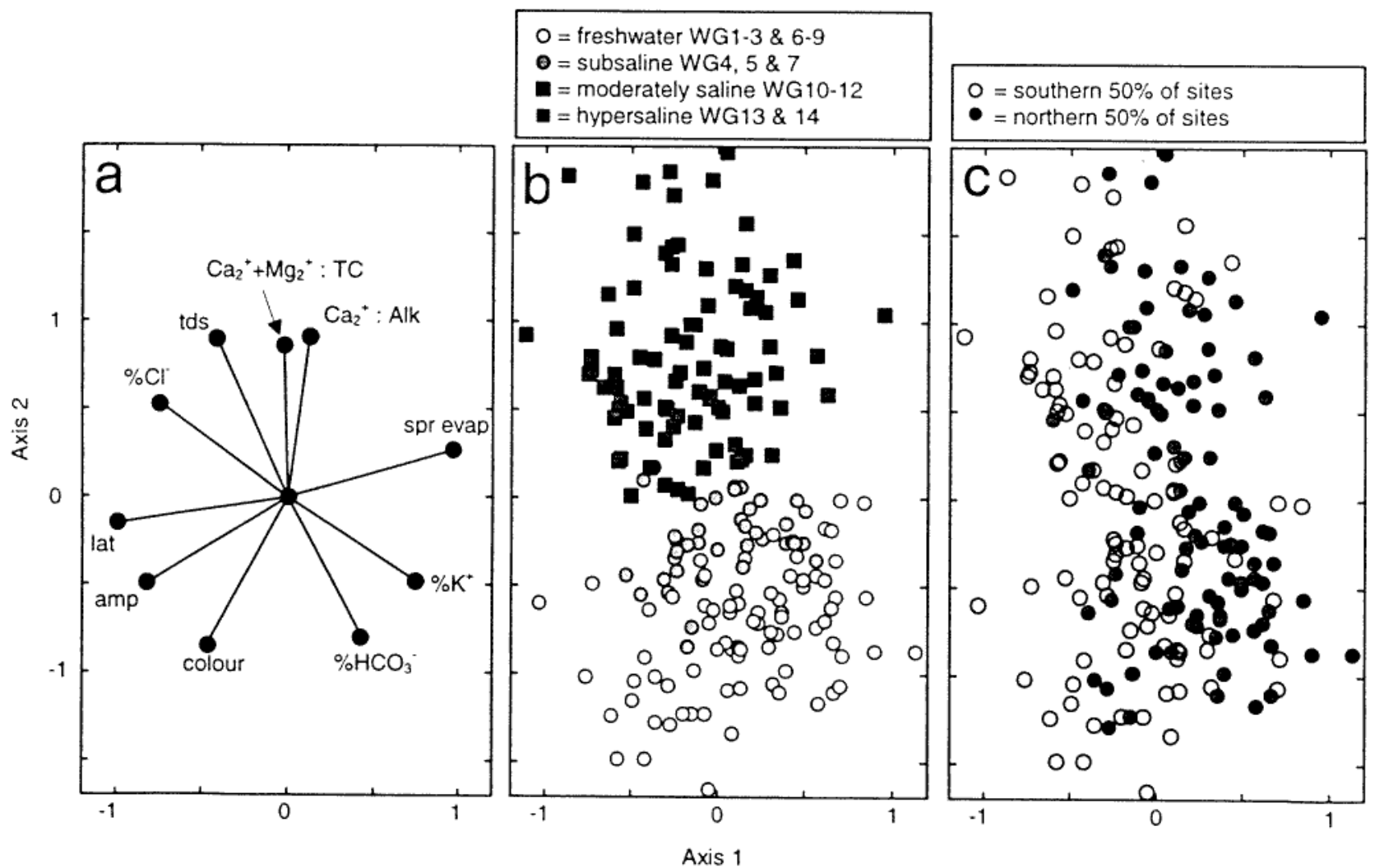

Figure 6 Ordination of wetland sites in the wheatbelt (stress 0.18) according to community composition showing (a) vectors of maximum correlation between environmental variables and wetland ordination axis scores, (b) wetlands in site groups amalgamated by salinity: freshwater groups (WG1 to $3 \& 6$ to 9), subsaline groups (WG4 \& 5), moderately saline groups (WG10 to 12) and hypersaline groups (WG13 \& 14) and (c) wetlands separated by latitude. See Table 3 for list of environmental variables. 
Table 3 Multivariate correlations ( $r$ ) between environmental attributes and ordination vector scores

\begin{tabular}{|c|c|c|c|}
\hline Variable & $\begin{array}{l}\text { ordination of } \\
\text { all wetlands }\end{array}$ & $\begin{array}{l}\text { ordination of lentic } \\
\text { freshwater wetlands } \\
\text { (groups 1-3\& 8-9) }\end{array}$ & $\begin{array}{l}\text { ordination of saline } \\
\text { wetlands (groups } \\
10-14 \text { ) }\end{array}$ \\
\hline $\mathrm{pH}$ & $0.28(1)^{* * *}$ & $0.51 * *$ & $0.76^{* * *}$ \\
\hline total nitrogen & $0.34(1)^{* * *}$ & $0.48(2) * *$ & $0.37(1)^{* *}$ \\
\hline total phosphorus & $0.31(3)^{* * * *}$ & $0.68(1) * * *$ & 0.19 (1) n.s. \\
\hline chlorophyll & $0.20(1) *$ & $0.43(1)^{* *}$ & 0.17 (1) n.s. \\
\hline turbidity & $0.33(1)^{* * *}$ & $0.53(1)^{* * *}$ & $0.44(1)^{* * *}$ \\
\hline colour & $0.70(1)^{* * *}$ & $0.63(1)^{* * *}$ & $0.52(1)^{* * *}$ \\
\hline total dissolved solids & $0.90(1)^{* * *}$ & $0.65(1)^{* * *}$ & $0.72(2)^{* * *}$ \\
\hline alkalinity & $0.24(2) * *$ & $0.65(2)^{* * *}$ & $0.65(1)^{* * *}$ \\
\hline hardness & $0.86(1)^{* * *}$ & $0.78(1)^{* * *}$ & $0.63(2)^{* * *}$ \\
\hline silica & $0.34(3)^{* * *}$ & 0.26 (1) n.s. & $0.58(1)^{* * *}$ \\
\hline$\%$ meq $\mathrm{Na}^{2}$ & $0.46(4)^{* * *}$ & 0.19 (4) n.s. & $0.45^{* * *}$ \\
\hline$\% \operatorname{meq} \mathrm{Ca}^{2}$ & $0.49(1)^{* * *}$ & $0.40(1)^{*}$ & $0.19(2)$ n.s. \\
\hline$\%$ meq $\mathrm{Mg}^{2-}$ & $0.37^{* * *}$ & $0.44^{* *}$ & $0.45^{* * *}$ \\
\hline$\%$ meq K & $0.58(1)^{* * *}$ & $0.56(1)^{* * *}$ & 0.18 (1) n.s. \\
\hline$\% \mathrm{meq} \mathrm{Cl}^{-}$ & $0.66(5)^{* * *}$ & $0.49(4) * * *$ & $0.43(4)^{* * *}$ \\
\hline$\%$ meq $\mathrm{HCO}_{3}$ & $0.86(1)^{* * *}$ & $0.43(2)^{* * *}$ & $0.61(3)^{* * *}$ \\
\hline$\% \mathrm{meq} \mathrm{SO}_{4}^{2}$ & $0.25(2)^{* *}$ & 0.17 (1) n.s. & $0.32(1) *$ \\
\hline monovalent : divalent cations & $0.33(1)^{* * *}$ & 0.30 (1) n.s. & $0.45(1)^{* * *}$ \\
\hline $\mathrm{Ca}^{2+}+\mathrm{Mg}^{2+}: \mathrm{Cl}$ & $0.46(1)^{* * *}$ & 0.24 n.s. & $0.47^{* * *}$ \\
\hline $\mathrm{Ca}^{2+}: \mathrm{Cl}$ & $0.50(1)^{* * *}$ & 0.17 (1) n.s. & $0.23(2)$ n.s. \\
\hline $\mathrm{Ca}^{2+}: \mathrm{SO}_{4}^{2-}$ & $0.52(1)^{* * *}$ & 0.21 (1) n.s. & 0.14 n.s. \\
\hline $\mathrm{Ca}^{2-}:$ alkalinity & $0.76(1) * * *$ & $0.43(1)^{* *}$ & $0.68(2) * * *$ \\
\hline total dissolved solids: alkalinity & $0.84(1)^{* * *}$ & $0.45(1)^{* *}$ & $0.77(1)^{* * *}$ \\
\hline hardness : salinity & $0.26(2) * *$ & $0.42(1)^{* *}$ & $0.44^{* * *}$ \\
\hline divalent cations: total carbonates & $0.82(1)^{* * *}$ & $0.55(1)^{* * *}$ & $0.72(1)^{* * *}$ \\
\hline latitude & $0.51 * * *$ & $0.51 * * *$ & $0.53^{* * *}$ \\
\hline longitude & $0.28 * *$ & 0.20 n.s. & $0.47^{* * *}$ \\
\hline elevation & $0.45^{* * *}$ & $0.44^{* *}$ & 0.25 (4) n.s. \\
\hline annual mean temperature & $0.51^{* * *}$ & $0.50 * * *$ & $0.53^{* * *}$ \\
\hline annual mean precipitation & $0.76^{* * *}$ & $0.79 * * *$ & $0.54(1)^{* * *}$ \\
\hline coeff. variation in precipitation & $0.31^{* * *}$ & 0.18 n.s. & $0.41 * *$ \\
\hline precipitation of driest quarter & $0.47^{* * *}$ & $0.46^{* *}$ & $0.50^{* * *}$ \\
\hline spring evaporation & $0.60 * * *$ & $0.64 * * *$ & $0.52 * * *$ \\
\hline
\end{tabular}

Numbers in brackets refer to transformations: $1=\log _{\text {w }} 2=$ square root, $3=$ reciprocal root, $4=$ squared, $5=$ cubed Correlations are significant at $P<0.001\left(^{* * *}\right),<0.01\left(^{* *}\right),<0.05\left({ }^{*}\right)$ or n.s. $=$ not significant

\section{Sediments and invertebrates}

Wetland sediments were characterised for the 60 wetlands in the northern Wheatbelt. These wetlands were classified according to the composition of their invertebrate faunas and between-group differences in sediment characteristics were determined by analyses of variance. This resulted in a classification with seven groups of sites: group 1 hypersaline playas (salinity 47 to $180 \mathrm{~g} \mathrm{~L}^{-1}$ ); group 2 - moderately saline wetlands ( 16 to $74 \mathrm{~g} \mathrm{~L}^{-1}$ ); group 3 - low salinity and often secondarily saline wetlands (4.2 to $14 \mathrm{~g} \mathrm{~L}^{-1}$ ); group 4 -granite outcrops; group 5 - freshwater swamps; group 6 shallow freshwater claypans; group 7 - rivers. Analyses of variance revealed significant betweengroup differences in \%clay (low in rivers and swamps, variable in salt lakes and high in claypans), \%sand (high in rivers and swamps, variable in salt lakes and low in claypans), texture of subsurface sediments (clay-loam to light clays in salt lakes and claypans, sandy loams to loams in rivers and swamps), \%gypsum (high in moderately and highly saline wetlands, otherwise low to absent), $\mathrm{pH}$ (higher in moderately and highly saline lakes than other wetlands) and salinity (the three groups of saline sites differed from each other and from remaining groups). Texture of surficial sediment, \%stones, \%silt and \%organic carbon were not significantly different between groups.

\section{Rarity}

Most species occurred infrequently, with twothirds present at fewer than 6 wetlands and only about $10 \%$ present at more than $10 \%$ of sites. The 274 species collected only once represented about a third of those present in the 202 samples used for the analyses, but their pattern of occurrence is not accounted for in the above analyses, from which they were excluded. Almost half of all singleton species occurred in just 19 wetlands, each of which 

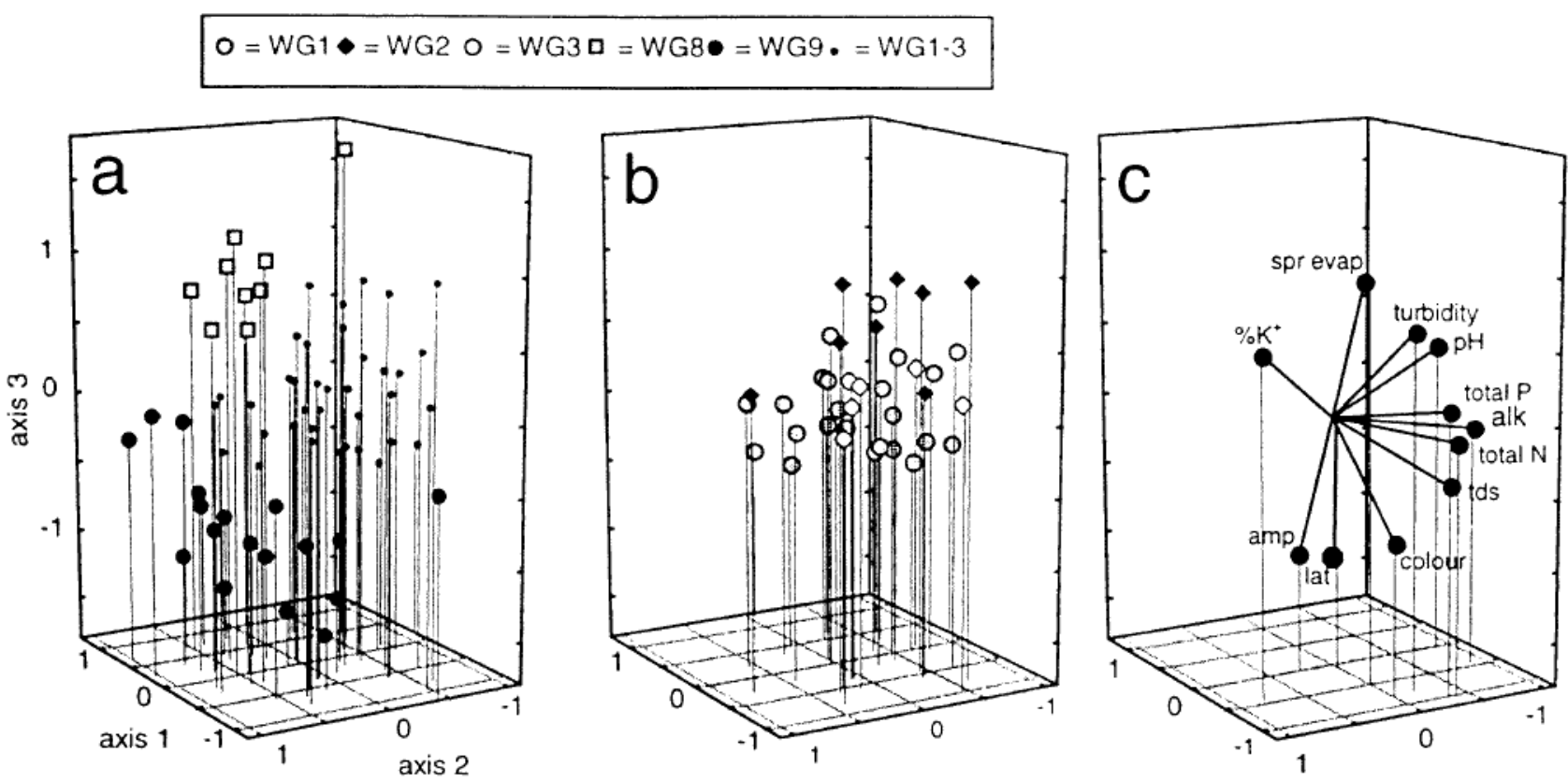

Figure 7 Ordination of freshwater lentic wetlands (stress 0.19) according to community composition showing (a) granite outcrops (WG8) and southern swamps (WG9) separate from wetlands of WG1 to WG3, (b) same plot rotated to show maximum separation of WG1 to WG3 and (c) vectors of maximum correlation between environmental variables and wetland ordination axis scores.

had 5 to 12 singleton species (Figure 9). These sites all had fresh water and were either swamps and rivers located along the southern and western edges of the Wheatbelt or were claypans and one granite outcrop along the eastern edge of the northern Wheatbelt. This pattern is indicative of peripheral rarity (Hengeveld and Haeck, 1982) and it is certainly the case that numerous species, such as the beetle Sternopriscus marginatus, mosquito Culex latus and caddisfly Triplectides niveipennis are more common in the higher rainfall areas of the southwest and/or south-eastern Australia (e.g. Liehne, 1991; St. Clair, 2002; Storey, 1998; Watts, 1978). Other invertebrates, such as the beetle Neohydrocoptus subfasciatus, oligochaete Pristina proboscidea, ostracod Zonocypretta kalimna and fairy shrimps Branchinella occidentalis and B. simplex are more common in northern and/or inland Western Australia (e.g. Halse, Shiel et al., 2000; Pinder, 2001; Timms, 2002) and mostly occurred in the northern or eastern Wheatbelt in this survey. For these 'peripheral' species, protection of wetland habitat in the Wheatbelt is probably not crucial to their conservation. For other species, especially new species and most of those assigned morphospecies codes, little to nothing is known of their distributions and environmental responses so it is difficult to plan for their conservation, other than adding them to the lists of species occurring in the wetland types identified from the above analyses (Table 2). The majority of singleton species were collected from fresh to subsaline wetlands (Table 2), where they accounted for $32 \%$ of all species collected from wetlands in WG1 to WG9. Salt lakes of WG10 to WG14 had fewer singleton species, both in absolute numbers ( 18 species from 82 wetlands $=$ $0.22 \pm 0.07 / \mathrm{site}$ ) and as a proportion of the total number of species occurring in salt lakes $(9.3 \%)$. Salt-lake singletons were halophilic ostracods, cladocerans, copepods, brine shrimps, rotifers, mosquitoes and Coxiella snails and most were new species.

\section{Salinity and salinisation}

All of the above analyses point to salinity being a major influence on the distribution of aquatic invertebrates in the Wheatbelt. In particular, the salinity range 10 to $20 \mathrm{~g} \mathrm{~L}^{-1}$ was associated with a major shift in community composition, although change was evident at even lower salinities. The latter is indicated by separation of most subsaline wetlands from freshwater wetlands in the classification and correlation of salinity with community structure, even when groups of freshwater wetlands were ordinated separately. Salinity was also associated with community composition in salt lakes, but, to a large extent, groups from the cluster analysis probably represent unstable divisions along a gradient of community change in response to salinity (albeit modified by the occurrence of secondary salinity, $\mathrm{pH}$ and possibly geography) rather than robust discontinuities in community composition.

Many of the wetlands in the survey once held freshwater but are now secondarily salinised to varying degrees. In such wetlands, altered 

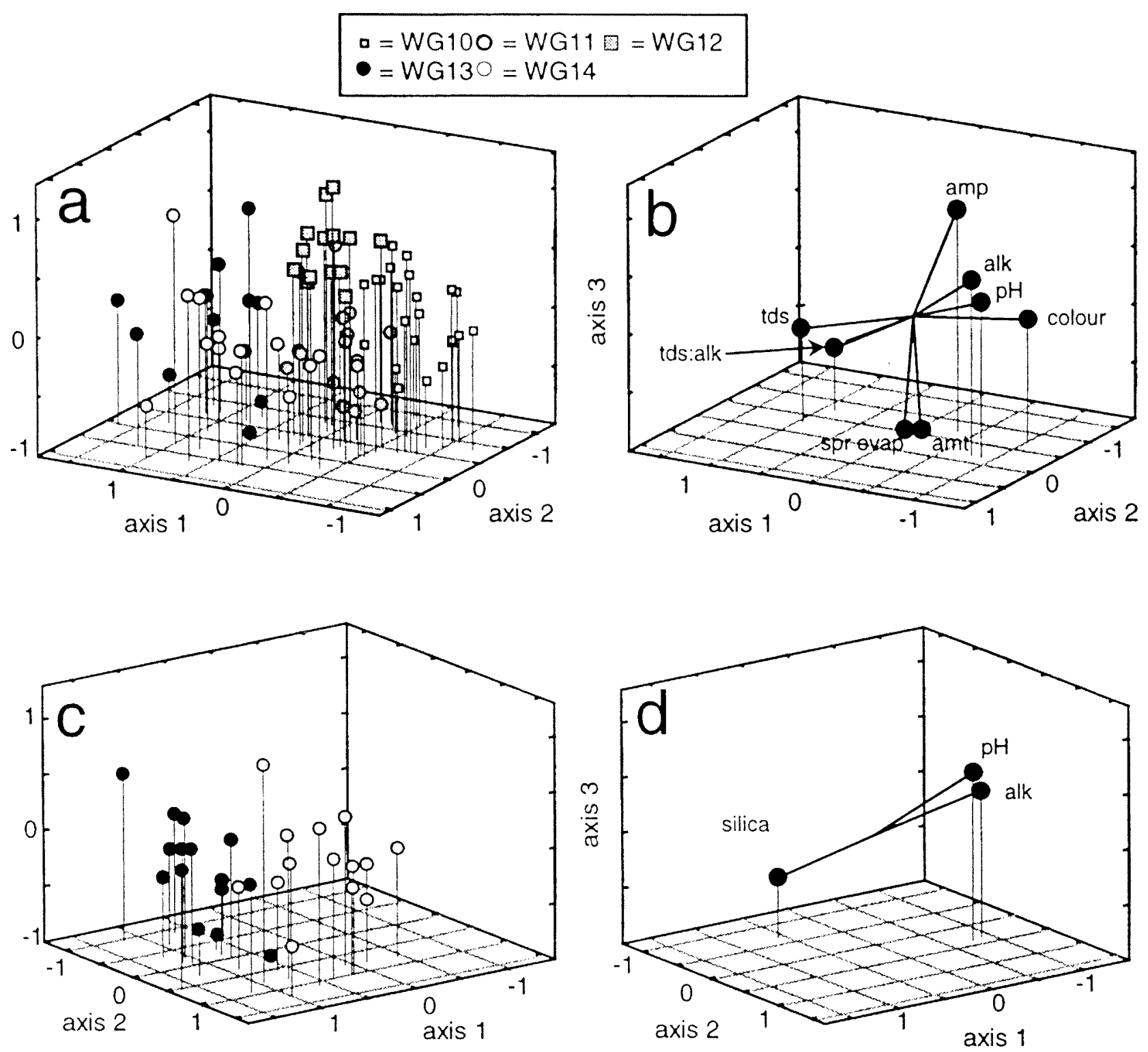

Figure 8 Ordination of saline lentic wetlands (stress 0.19 ) according to community composition showing (a) position of wetlands in WG10 to WG14, (b) plot of vectors of maximum correlation between environmental variables and wetland ordination axis scores from same perspective, (c) wetland ordination rotated to show separation of WG13 from WG14, (d) plot of vectors of maximum correlation between environmental variables and wetland ordination axis scores from same perspective.

community composition was detected even at quite low salinities as the most salt-sensitive freshwater species disappear and halophilic species begin to colonise. Initially, below about $4 \mathrm{~g} \mathrm{~L}^{-1}$, loss of freshwater species is offset by a gain in halophilic species such as the ostracods Mytilocypris tasmanica chapmani and Diacypris spinosa. However, with further increases in salinity, total richness declines and communities undergo further change, involving loss of species with moderate salinity tolerance, such as the ostracod Alboa woora (present at salinities $\leq 22 \mathrm{~g} \mathrm{~L}^{-1}$ ) and the beetle Antiporus gilberti (present to about $12 \mathrm{~g} \mathrm{~L}^{-1}$ ), and colonisation by a smaller suite of halophiles such as the midge Tanytarsus barbitarsus and the ostracod Australocypris insularis. At salinities above about 15 to $20 \mathrm{~g} \mathrm{~L}^{-1}$ the species pool in once freshwater wetlands is largely restricted to a limited suite of widespread salt-tolerant or halophilic invertebrates. Figure 10 shows the decline in species richness as salinity increases. It is important to note, however, that in freshwater wetlands that have become saline, invertebrate communities do not simply converge towards those of natural salt lakes, as the latter support many species (most of assemblage G) not found in freshwater wetlands that have become saline.

However, naturally saline lakes that were affected by secondary salinisation also had lower richness of species from assemblage $G$ than did minimally disturbed salt lakes. The eight most clearly degraded natural salt lakes (such as Pickersgill 


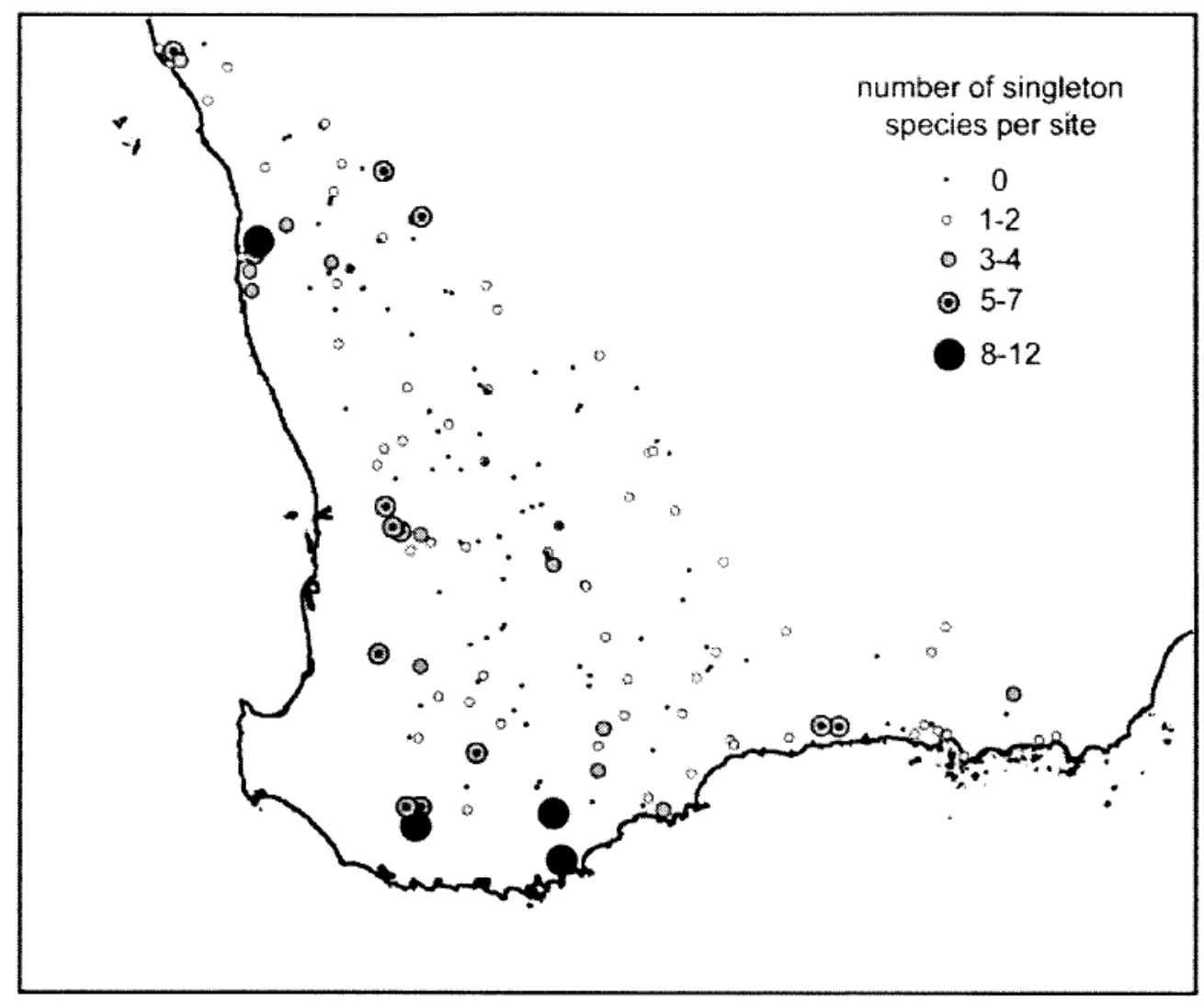

Figure 9 Map of the wheatbelt showing richness of singleton species at each wetland.

Lake, SPS066 and Anderson's Lake SPS106) had an average of $2.2 \pm 0.6$ species from assemblage $G$ whereas 24 minimally disturbed salt lakes had $3.6 \pm$ 0.3 . Average salinity was about the same in both disturbed and undisturbed lakes $\left(90.8\right.$ and $87.0 \mathrm{~g} \mathrm{~L}^{-1}$ respectively) and wetlands with $\mathrm{pH}<5$ were disregarded to exclude $\mathrm{pH}$ as a confounding factor. Individual species were too patchily distributed to assess the significance of their absence from disturbed salt lakes.
The 13 lakes with $\mathrm{pH}<4.0$ tended to have particularly depauperate communities and numerous salt lake species common in alkaline lakes of comparable salinity were absent or much less common in these systems, including the ostracods Platycypris baueri and several Diacypris (fodiens, whitei and a new species) and the copepod Meridiecyclops baylyi. Some species, such as the ostracod Australocypris bennetti, occurred independently of $\mathrm{pH}$ while others showed an

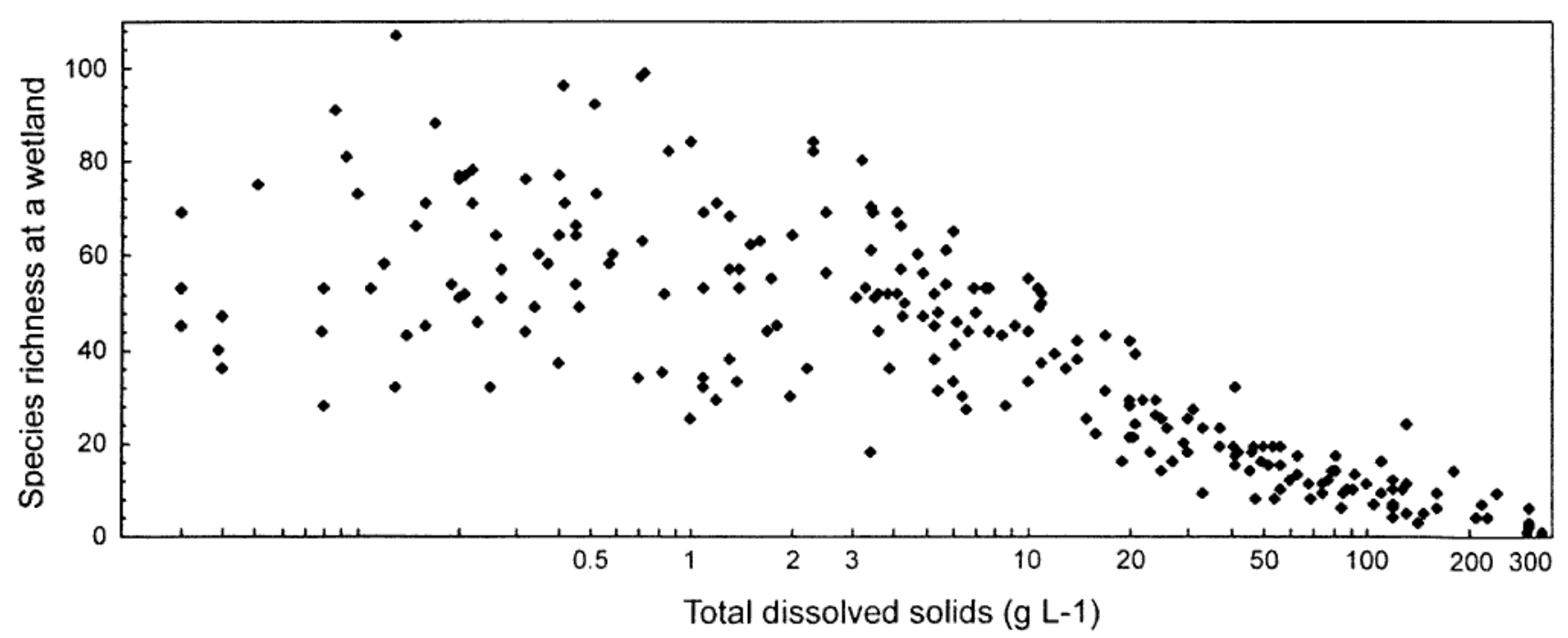

Figure 10 The relationship between salinity and aquatic invertebrate richness, each point representing one sampling occasion. 
affinity for acidic salt lakes (Parartemia contracta, Reticupris sp. 556, Calamoccia trilobata and possibly Diacypris sp. 523).

\section{Invertebrates in artificial wetlands}

A total of 314 taxa were collected from the 22 artificial wetlands (farm dams, fire dams, excavated damplands and town water șupply reservoirs). This is about $40 \%$ of the total number of species (801) collected in all 97 natural wetlands in the same salinity range $\left(0.05\right.$ to $\left.6.4 \mathrm{~g} \mathrm{~L}^{-1}\right)$ and $28 \%$ less than the number of species expected from the same number of natural wetlands $(434 \pm 2.52$, range $384-$ 491 , based on 100 random selections of 22 sites). Composition of communities in artificial wetlands differed from that of natural wetlands, with insects over-represented in the former by about $10 \%$ and microinvertebrates under-represented by about the same proportion. Thirty-six species were collected only from artificial wetlands, including five new rotifers and crustaceans (Filinia n. sp., Ilyodromus sp. 561, Alona n. sp. d, Daphnia n. sp. c, Branchinella halsei), but most of these were collected only once. Exceptions include the cosmopolitan oligochaete Tubifex tubifex, the clam Musculium kendricki and the water mite Hydrodroma sp. B, each of which occurred in 3 or 4 dams but not in natural wetlands, and the introduced yabbie Cherax destructor was mostly collected in artificial wetlands.

\section{DISCUSSION}

\section{Diversity, distribution and endemism}

The Wheatbelt region has been shown to have a rich aquatic invertebrate fauna with some unique elements. The number of aquatic invertebrates identified from the Wheatbelt has increased fivefold as a result of this survey, from around 200 in existing literature to almost 1000 . At least $17 \%$ are either new undescribed species or have not previously been recorded from south-western Australia. Most of these are rotifers, cladocerans or ostracods, reflecting the paucity of study of aquatic microfauna in Western Australia. This richness was certainly higher than anticipated from such a cleared and highly salinised landscape but the large area surveyed, inclusion of several biogeographic regions, presence of a broad array of wetland types and an apparent radiation of crustaceans inhabiting salt lakes and ephemeral waters of the south-west, no doubt contributed to the diversity found.

Comment on regional affinities of the Wheatbelt fauna is hampered by taxonomic uncertainty, incompatible coding of morphospecies between this survey and other published studies, and by the fact that some groups are poorly surveyed elsewhere in the State. Nonetheless, there is sufficient information for about 650 species to make some observations about distribution patterns. About two-thirds of the species also occur in south-eastern Australia and some are even more widely distributed, including a few with global distributions. Most of these widespread species occur throughout the south-west but many of the halophiles are more common in the Wheatbelt and perhaps further east (where salt lakes also predominate) than elsewhere in the State. About 30 species, mostly recorded from the northern or eastern Wheatbelt in this survey, represent a widespread but more northern or inland component of the fauna. These are mostly beetles like Hydrochus lateviridis and Batrachomatus wingi or rotifers like Lecane papuana and Lecane furcata but also include the midges Polypedilum leei and Tanytarsus sp. G (now recorded from the Pilbara region - unpublished data) and mosquito Culex palpalis. The remaining species are presently known only from south-western Australia.

Endemism within the south-western Australian biota has long been recognised for some groups, especially plants (Beard et al., 2000), but the extent of endemism within the region's aquatic invertebrate fauna has gone unrecognised until relatively recently (e.g. Geddes et al., 1981; Halse, Shiel et al., 2000; Horwitz, 1997; Storey et al., 1993). Even within relatively well-studied groups, such as some of the insect orders, recent work has revealed greater endemism than previously recognised (e.g. Dean, 2000; Hendrich, 2001a,b; St. Clair, 2002; Watts, 1997; Watts and Pinder, 2000). Among noninsect groups, the restriction of most species of Parartemia brine shrimp and Coxiella snails to southwestern Australia is well established (Geddes, 1981; MacPherson, 1957) but there is growing recognition that other groups, such as fairy shrimps (Branchinella), rotifers, oligochaetes and microcrustaceans, have also undergone substantial speciation in south-western Australia. This picture has been enhanced by the present study and other recent surveys (Halse, Shiel et al, 2000; Horwitz, 1997; Kay et al., 2001) and taxonomic work (e.g. Frey, 1991,1998; Halse and McRae, 2001,2004; Hebert and Wilson, 2000; Pinder, 2002; Pinder and Brinkhurst, 1997; Segers and Shiel, 2003; Timms, 2002). Such diversification in the south-western Australian aquatic fauna is plausibly attributable to a combination of the great age and geological stability of the landscape, strong climatic gradients and high diversity of aquatic habitats in the region, adaptation to salinity and aridity during periods of climatic fluctuation and genetic isolation from the eastern Australian biota (Frey, 1991; Geddes et al., 1981; Halse, 2002; Hebert and Wilson, 2000; Timms, 2002). Species adapted to salinity and/or ephemerality appear to constitute the bulk of regionally endemic species and Geddes et al. (1981) suggested that south-western Australia has been the 
centre of evolution for many genera found in Australian salt lakes. A recent survey of global freshwater biodiversity (Thomsen, 1999) listed south-western Australia as a hotspot for brineshrimp (from saline waters) and fairy shrimp (mostly ephemeral freshwater) and most of these are species of the Wheatbelt or further inland.

On existing information, just over 200 species in Appendix 3 appear to be endemic to the south-west (considered here to include the Carnarvon Basin), but this figure is approximate because many areas of Australia remain poorly surveyed for aquatic invertebrates. Rotifers and cladocerans in particular, which make up a quarter of these presumed endemics, have not been well surveyed across much of the country and only limited comment can be made on their broader occurrence. Notably, several rotifers and cladocerans first recorded in this project or in the Carnarvon Basin (Halse, Shiel et al., 2000) have recently been found in the Eyre Basin (R.J. Shiel, unpublished data, National Heritage Trust AridFlo project). On the other hand, some species tentatively identified as widespread forms may turn out to be restricted to Western Australia once more detailed taxonomic work is undertaken. For example, the cladoceran Daphniopsis pusilla, once considered to be widespread, is now known to be restricted to south-western Australia (Hebert and Wilson, 2000). In this survey, the potentially endemic rotifer species were all undescribed, mostly identified for the first time during the project and mostly recorded just once. Almost all were from relatively undisturbed seasonal freshwater wetlands of the Jarrah Forest, Esperance Sandplains, Geraldton Sandplains or in the far northern extent of the Avon-Wheatbelt. The potentially endemic cladocerans were also mostly undescribed, except for some of the granite outcrop species and Daphniopsis spp. from salt lakes. Compared to rotifers, a larger proportion of cladocerans occurred well inland (Avon Wheatbelt and Mallee regions), though most were still restricted to freshwater habitats. Only one of the rotifers (Keratella n. sp.) and one of the cladocerans (Daphniopsis pusilla) were collected in the Carnarvon Basin by Halse, Shiel et al. (2000).

For those presumed south-west endemics that are better-studied, previous work in the south-west and Carnarvon Basin provides a framework for allocating distribution patterns (ARL, 1992; Bayly, 1992; Bunn, 1986; Davis et al, 1993; Edward et al., 1994; Horwitz, 1994; Pusey and Edward, 1990; Storey, 1998; Storey et al., 1993 and unpublished data). Distributions fit three broad patterns. Firstly, most of the insects, water mites, annelids, Cherax crayfish, molluscs and a few ostracods (altogether about 50 species) appear to occur predominantly in freshwater wetlands of coastal or higher rainfall parts of the south-west. In this survey, such species tended to occur mostly in the Jarrah Forest and Esperance Sandplains bioregions, although a few occurred in wetlands on the Geraldton Sandplains. Secondly, invertebrates such as Coxiella snails, Parartemia brine shrimps, Branchinella fairy shrimps, Paroster beetles, some copepods and cladocerans and a large number of ostracods (together comprising about 65 species) appear to have more inland or eastern distributions and, in this survey, tended to occur mostly in the Avon-Wheatbelt and Mallee bioregions or in the eastern Esperance Sandplains. Most of these inhabit granite outcrop pools or salt lakes (particularly the naturally saline playas). They were not collected in the Carnarvon Basin survey but may occur in suitable habitat in the Goldfields region east of the Wheatbelt, although diversity is likely to attenuate with increasing aridity (De Deckker, 1983; Williams, 1998a). Lastly, 30 or so species are more widespread in the south-west, occurring widely in the Wheatbelt but also in the Carnarvon Basin and/or the mesic south-west.

With respect to overall similarities with other regions, about $20 \%$ of the species in Appendix 3 were also collected in the southern Carnarvon Basin by Halse, Shiel et al. (2000). This is probably a reasonably accurate estimate of similarity except for the difficulty of comparing some of the dipteran families. Species in common represent about $40 \%$ of the Carnarvon Basin fauna and are mostly widespread in Australia, though a few (e.g. Branchinella halsei and Uvarus pictipes) are endemic to southern Western Australia. Comparisons with other published studies (listed above) indicate that regions to the south-west of the Wheatbelt (western Jarrah Forest, Warren and Swan Coastal Plain bioregions) share at least $27 \%$ of species in Appendix 3. However, inconsistent morphospecies coding and the fact that groups such as rotifers and oligochaetes were not identified in these other studies, suggest this is likely to be a gross underestimate of similarity.

\section{Wetland invertebrate communities}

The species collected at each wetland represent only a subset of those actually present at the time of sampling and those utilising the wetland through time. Previous analyses suggest that the sampling protocol used here collects around $60 \%$ of species present in the wetland at the time of collection (Halse et al., 2002) but Halse, Pearson et al. (2000) and Halse, Cale et al. (2002) concluded that this was sufficient to characterise wetland communities using multivariate analysis. Likewise, Growns et al. (1992) found that comparable sampling effort was sufficient to produce a useful classification of wetlands on the Swan Coastal Plain. Such characterisations are most easily translated into regional conservation planning when identified 
community types are uniquely associated with particular assemblages and occur in distinct and easily identifiable habitats. The extent to which this occurred in the survey was variable. Some of the wetland groups identified from the cluster analysis, such as granite outcrop pools (WG8), southern swamps (WG9), and rivers (WG6 and 7), clearly represented distinct habitat types and particular assemblages showed high fidelity to these. Other wetland groups included a broader array of habitats and their communities were distinguished only by differential richness of a range of assemblages. For instance, wetlands of WG4 and WG5 were mostly freshwater wetlands that had become slightly saline and their communities were distinct only in that they combined a salt-tolerant remnant of freshwater communities with a limited halophile element that has colonised since salinisation. Group WG1 also included a broad range of freshwater wetlands, ranging from sedge or tree-dominated swamps through to open ponds, and communities were highly heterogeneous, with only one small assemblage showing moderate fidelity to these wetlands. While WG3 wetlands were geographically restricted and represented a reasonably uniform habitat type (swamps dominated by trees) their communities appeared to be simply depauperate versions of those occurring in WG1. Communities of shallow claypans (WG2) were also largely species-poor versions of those in WG1 but, because a number of species showed a preference for such wetlands, recognising them as a distinct group has value for conservation planning. In saline wetlands, species-poor heterogeneous communities, together with broad salinity tolerance and rarity of most halophile species, made recognition of distinct community types particularly difficult. Some plavas, such as those in WG13 and WG14, consistently reached very high salinities (>100 $\mathrm{g} \mathrm{L}^{-1}$ ), even at high water levels, and their communities were distinct in that they included a number of species, such as Parartemia brine shrimp and some ostracods, that were uncommon at lower salinities. For a small number of acidohalophilic species, the low pH conditions in some WG13 wetlands were particularly important. The remaining natural but more moderately saline wetlands in groups WG11 and part of WG12 were essential habitat for numerous halophilic species that tended not to occur at the highest salinities, but their heterogenous communities prevented delineation of robust community types. Secondarily saline wetlands (most of those in WG10 and some of WG12) had communities that were distinct from natural salt lakes but are of limited conservation importance for invertebrates.

Assessing the validity and utility of the classification of Wheatbelt wetlands is difficult because there have been few Australian studies of comparable scope with which to compare our classification. Halse, Shiel et al. (2000) divided 56 Carnarvon Basin wetlands into five groups based on invertebrate communities: larger flowing streams, river pools and rock pools; smaller creeks, seeps and springs; freshwater claypans; birridas (coastal evaporite pans) and Lake MacLeod (a particularly large birrida). Compared with the Wheatbelt, there was a greater tendency for species assemblages to be restricted to particular wetland groups but the groups were more physiognomically distinct than many of those identified in the Wheatbelt. In the arid Paroo region of New South Wales and Queensland, Timms and Boulton (2001) classified 87 wetlands according to their invertebrate faunas. The wetland typology produced was broadly similar to that presented here for the Wheatbelt and consisted of "saline wetlands", "claypans", "vegetated depressions", "riverine waterholes" and "freshwater lakes". As for the Wheatbelt, many freshwater assemblages occurred across multiple wetland types but their relative importance in the types varied. Groupings of the Paroo saline wetlands more-or-less corresponded to the subsaline (WG4-5), moderately saline (WG10-12) and hypersaline (WG13-14) groupings in the Wheatbelt. Significantly however, considering the difficulties of distinguishing robust community types in Wheatbelt salt lakes, Timms and Boulton (2001) concluded that saline lakes are appropriately considered as a single entity in any wetland classification because of their wide fluctuations in salinity and the broad salt tolerance of their fauna. Most other surveys have been restricted to particular types of wetlands and so are not of comparable scope. For example, the 41 sites on the Swan Coastal Plain surveyed by Growns et al. (1992) were all lentic basin wetlands. In that survey, three mildly saline lakes and a secondarily acidic lake were outliers but the remaining wetlands, all freshwater, grouped according to physico-chemistry (nutrients and colour) and seasonality. Fidelity of assemblages to wetland groups was greater than in the present survey, with six of the nine assemblages showing high fidelity to particular groups of wetlands.

\section{Environmental influences on invertebrate occurrence}

Hawkins et al. (2003) suggest that contemporary climate explains much of variation in species richness over large scales. This survey certainly showed that geographic position and climate influence distribution patterns of the fauna at the regional scale, probably acting through their influence on hydrology, salinity, extent of secondary salinisation and distribution of particular habitats such as flowing water, granite outcrops and claypans (see Figure 8 in Halse et al., 2003). At a 
more local scale, salinity is clearly a key determinant of community composition and assemblage richness, though turbidity, flow and $\mathrm{pH}$ are important in some situations.

\section{Geographic position and climate}

Geographic position and climate are most likely to influence species occurrence at scales larger than those of most studies. The association of latitude and longitude with community composition in Carnarvon Basin wetlands reflected distribution of certain habitat types in the region, and possibly correlations with other variables such as flow in rivers and salinity rather than large-scale zoogeographic patterning (Halse, Shiel et al., 2000). The same probably applied in Kay et al.'s (1999) survey of north-western Australia, which found regional differences in the family-level composition and richness of riverine communities in northwestern Australia, although individual families tended not to have restricted distributions. In the Wheatbelt, the main faunal gradient in response to geographic and climatic variables extended from the south-west and coastal regions to the north-east and inland. Thus, the southern swamps of WG9 and the active rivers of WG6 and 7, were located on the south-west and coastal limits of the study area, with saline wetlands and other types of freshwater tending to occur further inland or north. Communities in rivers flowing to the south and west coasts were clearly different from each other and from those of the inland palaeodrainage channels, confirming a weaker pattern noted in a family-level analysis of riverine communities by Kay et al. (2001). Geography and climate were also parameters in most of the assemblage richness models, usually reflecting the same south-west/ north-east gradient. However, some apparent geographic patterns, particularly the spatial separation of the subsaline groups (WG4 and WG5) and saline groups (WG11 and WG12), should be viewed with caution because the northern, central and southern parts of the Wheatbelt were sampled under different climatic conditions and differentiation between these groups may be artefactual.

\section{Salinity and secondary salinisation}

Salinity was a strong parameter in most of the assemblage richness models, was significantly and strongly correlated with community composition in ordinations and varied substantially between many of the wetland groups derived from the cluster analysis. The salinity range 10 to $20 \mathrm{~g} \mathrm{~L}^{-1}$ appeared to be associated with a particularly rapid shift in community composition, although compositional changes were evident at even lower salinities. Response of aquatic invertebrate communities to low levels of salinity has been shown elsewhere (e.g. Timms, 1993), including lakes of the far southwest coast of Western Australia, where maximum salinity was $<3 \mathrm{~g} \mathrm{~L}^{-1}$ (Edward $e t$ al, 1994). In this survey, richness of the two assemblages that showed most sensitivity to salt tended to be greatest in higher rainfall belts, suggesting that the assertion of Horwitz (1997) that salt sensitive species in the Warren region are most likely to occur along the higher rainfall coast applies at a larger and more general scale to south-west Western Australia as a whole. Nonetheless, community composition of wetlands within drier areas also showed variation in response to small changes in salinity, as shown by separation of freshwater communities of WG1 to WG3 from the subsaline communities of WG4 and WG5. Within saline wetlands, salinity thresholds associated with substantial differences in community structure were less evident. While richness certainly responded to large changes in salinity, so that wetlands with the highest salinities $\left(>100 \mathrm{~g} \mathrm{~L} \mathrm{~L}^{-1}\right.$ ) have particularly depauperate communities, most halophiles had broad salinity tolerances and subgroupings of the highly heterogeneous communities in more moderately saline wetlands were not obviously related to salinity per se. Timms (1993) and Williams (1981) also noted that many salt lake species occurred across broad ranges of salinity and that, while salinity was important, it was not sufficient by itself to explain much of the variation in salt lake communities. This idea was expanded upon by Williams et al. (1990), who found a strong relationship between salinity and aquatic invertebrate community composition in wetlands when the full salinity spectrum was considered, but suggested that other (unidentified) biotic and abiotic variables were likely to be as important, or more important, within narrower ranges of salinity. The influence of a number of such variables on salt lake communities ( $\mathrm{pH}$, ionic composition, oxygen, hydrologic patterns and stochastic events) was reviewed by Williams (1998b). Our results lend support to this concept, with salinity being strongly related to the higher level divisions of the wetland classification and contributing to many of the assemblage models, but other variables (including $\mathrm{pH}$ and the effects of secondary salinisation) being important in particular situations and ranges of salinity.

Ionic composition, though known to influence occurrence of salt lake species (Herbst, 2001; Mezquita et al., 1999; Radke et al., 2003; Timms, 1983), was remarkably uniform in Wheatbelt salt lakes and there was little evidence that it was important at the community or assemblage level. In general, correlations of particular ionic concentrations and ion ratios with community composition and assemblage richness appeared only to reflect the greater diversity of ionic 
composition in freshwater wetlands, where precipitation pathways are inconsequential, or resulted from correlations between bicarbonate concentration, salinity and $\mathrm{pH}$ rather than any discernible direct effect of ionic composition. Responses of individual salt lake species to ionic composition and precipitation pathways might be revealed by more detailed analvses such as those employed by Radke et al. (2003). One example of such a response that is frequently quoted (e.g. Williams, 1998b) is the suggestion of Bayly (1969) that a high ratio of total carbonates to chloride (Alk: $\mathrm{Cl}$ ) permitted the otherwise freshwater copepod Boeckella triarticulata to occur in salt lakes (up to $22 \mathrm{~g} \mathrm{~L}^{-1}$ in his Western Victorian lakes). However, Bayly (1969) qualified this observation by suggesting that Alk:Cl may only be important in rendering saline water with high monovalent:divalent cation ratio ( $>8$ in Bayly's lakes) non-toxic to some freshwater species. This qualification, not always noted by subsequent authors, is supported by our data. Boeckella triarticulata regularly inhabited wheathelt salt lakes (salinity up to $25 \mathrm{~g} \mathrm{~L}^{-1}$ ) despite low (0.03-0.005) Alk: $\mathrm{Cl}$, but the ratio of monovalent to divalent cations was also low (mostly 1 to 8 ).

Secondary salinisation and related processes of waterlogging and acidification are of critical importance to conservation of biodiversity in the Wheatbelt (Halse et al., 2003). A large proportion of species in Appendix 3 occurred only in freshwater or had limited salt tolerance and this survey has shown that freshwater wetlands subject to secondary salinity have dramatically reduced species richness and communities composed of a limited suite of halotolerant and halophilic species. A more detailed analysis of species' salinity tolerance (Pinder $e t$ al, in press) revealed that $54 \%$ of freshwater species were restricted to salinities below $3 \mathrm{~g} \mathrm{~L}^{-1}$ and $83 \%$ were restricted to salinities below $10 \mathrm{~g} \mathrm{~L}^{-1}$. However, these figures probably overstate the threat to the regional fauna because 1) we are likely to have under-sampled the salinity range of rare species, 2) not all freshwater wetlands will become saline and habitats such as freshwater seeps entering wetlands from perched aquifers provide low salinity microhabitats, 3) substantial seasonal and inter-annual fluctuations in salinity occur, especially freshening of wetlands after large floods and 4) pools on granite outcrops and artificial wetlands are likely to provide refuge for a substantial proportion of species (almost half the freshwater species occurred in such habitats during the survey). Halse t al. (2003), taking into account these ameliorating factors, suggested about onethird of freshwater species are at risk of extinction from the Wheatbelt. Also, some of the species that might disappear from the Wheatbelt will persist in other regions not threatened by salinity.
An important finding from this survey is that freshwater wetlands that have become saline are of little conservation value for many halophilic species, though reasons for this are not clear. Most naturally saline wetlands in the Wheatbelt have strongly seasonal hydrological and chemical regimes and life history events, such as egg production and hatching of drought-resistant propagules, are almost certainly cued to this environmental periodicity in some species (De Deckker, 1983; Geddes, 1981). Subdued seasonality in secondarily saline lakes most likely disrupts the reproductive cycle for such species, though little is known about the biology of most halophiles.

There was evidence that secondarily salinisation has detrimental effects on invertebrate communities of natural salt lakes, but detection of such effects was made difficult by low richness and inherent heterogeneity of highly saline communities and the rarity of most halophilic species. Halse et al. (1993) and Lyons et al. (2004) have demonstrated that secondary salinisation also has significant effects on the aquatic and fringing vegetation of natural salt lakes. Acid salt lakes are an unusual but, in some cases, natural feature of the Wheatbelt (Bettenay et al., 1964: Mann, 1983) and a few species occur predominantly in such conditions. Nonetheless, it was clear from the survey that acidic hypersaline wetlands have particularly depauperate communities. Secondary acidification, associated with rising groundwater and excavation of drainage channels in areas of ferric or sulfate soils, is thus a further threat to salt lake diversity.

\section{Assemblage modelling}

Some of the geographic, climatic and chemical variables measured in this survey certainly influenced the distribution of species in some situations but models based on them accounted for only 36 to $79 \%$ (mean $63 \%$ ) of variation in assemblage richness. There are several possible reasons why explanatory power was not higher: 1) invertebrates responded to variables not quantified in the survey, 2) many species were genuinely rare so their habitat envelope was inadequately sampled, 3) presence of species was inconsistently detected, 4) many species were tolerant of a wide range of conditions and 5) stochastic processes played a significant role in species distributions. Probably all of these affected modelling.

One complex variable (or suite of variables) that could not be quantified in sufficient detail in this type of spatially oriented survey was stage of the hydroperiod, although it is known to influence both spatial and temporal distributions of species (Hancock and Timms, 2001; Timms, 2001). Most wheatbelt wetlands are generally seasonal rather than episodic or permanent and all were sampled in late winter to mid-spring. However, local spatial 
and temporal differences in rainfall, hydrology and catchment morphology are likely to have caused wetlands to fill at different times to different depths prior to sampling. Williams (1981) noted that hydrological cycles of lakes can vary substantially, even within a restricted region, and Williams (2000) suggested that "local differences in hydrology, filling frequency, basin morphometry and other factors" interact so that wetlands in the same area will fill at different rates, resulting in a "mosaic of communities, each wetland somewhat different from others nearby". Shiel et al. (1998), studying microinvertebrates in freshwater billabongs, also suggested that heterogeneity of species dispersion mirrors heterogeneity of habitats, reflecting slight differences in hydrology, morphometry, substrates and vegetation. Past hydrological regimes are also likely to have influenced the species mix and viability of dormant propagules.

Microhabitat diversity within Wheatbelt wetlands was not quantified but is likely to have influenced the mix of species present. Although a quadratbased floristic survey of these wetlands was undertaken (Lyons et al., in press), quantitative measurements of vegetation within and around wetlands, such as cover and biomass, were not made. Sediment variables showed some association with invertebrate community composition in the northern Wheatbelt, (for example \%clay in sediments of freshwater wetlands might be a better correlate of assemblages inhabiting claypans than turbidity) but were not sampled at enough wetlands to enter into assemblage models. Pinel-Alloul et al. (1995) found that power to explain zooplankton composition was substantially higher when biotic and abiotic factors were considered together rather than alone. In the wheatbelt, biotic processes such as colonisation history and species interactions are likely to have played a role in structuring invertebrate communities and these can interact with salinity and hydrology (Colburn, 1998; Geddes, 1986; Mitchell, 1986; Sarma et al, 2002; Shiel et al., 1998) but are not readily incorporated into simple predictive models.

Dispersal of invertebrates and their propagules, via episodic flood events, wind dispersal from dry sediments, phoresy on birds and insects (see Figuerola and Green, 2002) and colonisation by flying insects can play an important role in invertebrate community structure. Jenkins and Buikema (1998), for instance, have shown that colonisation history can create different zooplankton communities in wetlands that are physico-chemically similar. Dispersal and colonisation however can be stochastic in nature and absence of a species from suitable habitat is likely to have been a matter of chance in many cases (Maly et al., 1997).

Finally, the structure of the data influences its amenability to modelling. Some assemblages, such as assemblage $D$, were sparsely distributed across a wide range of wetland types and were comprised of very infrequently occurring species. It is questionable whether these represented real assemblages in an ecological, as opposed to a statistical, sense and, if they did, whether their environmental responses can be successfully modelled with so few data points. Conversely, many species in Wheatbelt wetlands were extremely widespread and common, occurring across at least southern Australia and were seemingly tolerant of a wide range of conditions (e.g. the species comprising assemblage E). For these species, some of the variables that determine their occurrence will appear unimportant unless part of the variable's range that lies beyond the species' broad habitat envelope is sampled. For example, while most invertebrates in the Wheatbelt are adapted to seasonal hydrological regimes, many would not occur in more episodic habitats of arid regions further inland. Climate variables might contribute more strongly to predicting richness of these ecologically tolerant assemblages if a larger part of the State were considered.

\section{Summary}

The Wheatbelt has been shown to have a wide variety of wetland types inhabited by a rich and very diverse aquatic invertebrate fauna of largely southern Australian affinity. Many wetland habitats need to be included in conservation programs to protect this component of the biota, including naturally saline playas, coastal lakes and streams (with a variety of natural salinity and hydrological regimes) and freshwater wetlands of both high and low rainfall areas. A variety of freshwater wetlands, including claypans, granite outcrop pools and rivers as well as lakes and swamps, are required to provide adequate habitat for aquatic invertebrates in the region. Freshwater lakes and swamps had highest species richness but pools on granite outcrops and saline playas are especially important for a large proportion of species potentially restricted to the inland south-west. Salinity is a primary determinant of the occurrence of species and secondary salinisation has the potential to dramatically reduce aquatic biodiversity in the region. The diffuse nature of the threat posed by salinisation and the patchy distribution of most species means that conservation programmes will need to focus on catchment or landscape scale approaches to protecting the various wetland habitats identified in this survey if all Wheatbelt aquatic invertebrates are to be conserved. Recommendations for the protection of wetland habitat for the region's aquatic biota, including suggestions for high conservation value wetlands that might be included in the Natural Diversity Recovery Catchment program (Anonymous, 1996), 
are considered further by Halse it al. (2004) and Walshe et al. (2004).

\section{ACKNOWLEDGEMENTS}

Though too numerous to mention individually, we firstly wish to thank the many landowners who kindly allowed us to sample wetlands on their property and people from government agencies and community groups who assisted us in our quest for suitable wetlands. Many taxonomists checked voucher specimens and provided identifications: David Cartwright (ecnomids and mayflies), Iohn Dean (hydropsychids), Ros St. Clair (leptocerids), Ivor Lansbury (hemipterans), Chris Watts (beetles), Alice Wells (hydroptilids), John Hawking (lepidopterans and dragonflies), Gunther Theisinger (dragonflies), Pat Hutchings and Greg Rouse (polychaetes), Lester Cannon (temnocephalids), Mark Harvey (water mites), Don Edward (chironomids), Winston Ponder and Shirley SlackSmith (molluscs), John Bradbury (amphipods), Simon Judd (isopods), Pierre Horwitz (decapods), Alan Savage (brine shrimps), Brian Timms (conchostracans and fairy shrimps), Fred Govedich (leeches). Matt Williams provided advice on generalised linear modelling and other statistical procedures. David Cale undertook much of the wetland monitoring from which data were extracted for our analyses. Melita Pennifold sorted and identified many of the samples and Michael Smith and Winston Kay assisted with field work in 1997. Funding for this study was provided as part of the State Salinity Strategy.

\section{REFERENCES}

Anonymous (1996). Western Australian salinity action plan. Government of Western Australia, Perth.

APHA (1995). Standard nethods for the examination of water and wastewater. American Public Health Association, American Water Works Association and Water Environment Federation, Washington.

ARL (1992). Survey of the macroinvertebrate fauna and water chemistry of permanent lakes of the south coast of Western Australia. A report for the Department of Conservation and Land Management. The University of Western Australia, Aquatic Research Laboratory, Perth.

Bayly, I.A.E. (1969). The occurrence of calanoid copepods in athalassic saline waters in relation to salinity and ionic proportions. Verhandhusen Intermationale Vereingtury fur theoretische und angewandte Limnologie 17: $419-455$

Bayly, I.A.E (1982). Invertebrate fauna and ecology of temporary pools on granite outcrops in southern Western Australia. Australian Joumal of Marine and Freshuter Research 33: 599-606.

Bayly, I.A.E. (1992). The micro-crustacea and physicochemical features of temporary ponds near
Northcliffe, Western Australia. Joumal of the Royal Society of Western Australin 75: 99-106.

Bayly, I.A.E. (1997). Invertebrates of temporary waters in gnammas on granite outcrops in Western Australia. Joumal of the Royal Society of Western Australia 80: 167172.

Beard, J.S. (1997). Geomorphology, geology and palaeohydrology of the broad alluvial valleys of the Salt River System, Western Australia. Australian Journal of Earth Sciences 44: 751-765.

Beard, J.S. (1999). Evolution of the river systems of the south-west drainage division, Western Australia. Journal of the Royal Society of Western Australia 82: 147164.

Beard, J.S., Chapman, A.R. and Gioia, P. (2000). Species richness and endemism in the Western Australian flora. Journal of Biogeggraphy 27: 1257-1268.

Belbin, L. (1993). PATN users guide and technical reference. CSIRO Division of Wildlife and Ecology, Canberra.

Bettenay, E., Blackmore, A.V. and Hingston, F.J. (1964). Aspects of the hydrologic cycle and related salinity in the Belka Valley, Western Australia. Australian Journal of Soil Research 2: 187-210.

Blinn, D.W., Halse, S.A., Pinder, A.M., Shiel, R.J. and McRae, J.M. (2004). Diatom and micro-invertebrate communities and environmental determinants in the Western Australian wheatbelt: a response to secondary salinization. Hydrobiologia 528: 229-248.

Boesch, D.F. (1977). Application of numerical classification in ecological investigations of water pollution EPA-600/3-77-033. United States Environmental Protection Agency, Washington D.C.

Brock, M.A. and Shiel, R.J. (1983). The composition of aquatic communities in saline wetlands of Western Australia. Hydrobiologia 105: 77-84.

Bunn, S.E. (1986). Spatial and temporal variation in the macroinvertebrate fauna of streams of the northern jarrah forest, Western Australia: functional organization. Freshwater Biology 16: 621-632.

Cale, D.J., Halse, S.A. and Walker, C.W. (2004). Wetland monitoring in the Wheatbelt of south-west Western Australia: site descriptions, waterbird, aquatic invertebrate and groundwater data. Conservation Science Western Australia 5: 20-135.

Cartwright, D.I. (1997). Preliminary guide to the identification of late instar larvae of Australian Ecnomidae, Philopotamidae and Tasimiidae (Insecta: Trichoptera). Identification Guide No. 10. Cooperative Research Centre for Freshwater Ecology, Albury.

Clarke, C.J., George, R.J., Bell, R.W. and Hatton, T.J. (2002). Dryland salinity in south-western Australia: its origins, remedies, and future research directions. Australian fournal of Soil Research 40: 93-114

Colburn, E.A. (1998). Factors influencing species diversity in saline waters of Death Valley, USA. Hydrobiologia 158: 215-226.

Commander, D.P., Schoknecht, N., Verboom, W. and Cacetta, P. (2002). The geology, physiography and soils of wheatbelt valleys. In V. Read and Associates (ed.), Dealing with salinity in Wheatbelt valleys: processes, prospects and practical options, 1-27. Water and Rivers Commission: Perth (Available on CD). 
Cranston, P.S. (2000). Electronic guide to the Chironomidae of Australia (http://wwow science.uts.eduau/sasb/ chiropage) 28 Feb 2000.

Davis, J.A., Rosich, R.S., Bradley, J.S., Growns, J.E., Schmidt, L.G. and Cheal, F. (1993). Wetland classification on the basis of water quality and invertebrate community data. Vol. 6. Water Authority of Western Australia, Perth.

De Deckker, P. (1983). Notes on ecology and distribution of non-marine ostracods in Australia. Hydrobiologia 106: 223-234.

De Deckker, P. and Geddes, M.C. (1980). Seasonal fauna of ephemeral saline lakes near the Coorong Lagoon, South Australia. Australian Journal of Marine and Freshwater Research 31: 677-699.

Dean, J.C. (1999). Preliminary keys for the identification of Australian Trichoptera larvae of the family Hydropsychidae. Identification Guide No. 22. Cooperative Research Centre for Freshwater Ecology, Albury.

Dean, J.C. (2000). Descriptions of new Leptophlebiidae (Insecta: Ephemeroptera) from Australia. II. Kaninga, a new monotypic genus from south-western Australia. Records of the Western Australian Museum 20: 87-94.

Doupé, R. and Horwitz, P. (1995). The value of macroinvertebrate assemblages for determining priorities in wetland rehabilitation: a case study from Lake Toolibin, Western Australia. Journal of the Royal Society of Western Australia 78: 33-38.

Edward, D.H.D., Gazey, P. and Davies, P.M. (1994). Invertebrate community structure related to physicochemical parameters of permanent lakes of the south coast of Western Australia. Journal of the Royal Society of Western Australia 77: 51-63.

Figuerola, J. and Green, A.J. (2002). Dispersal of aquatic organisms by waterbirds: a review of past research and priorities for future studies. Freshwater Biology 47 : 483-494.

Frey, D.G. (1991). The species of Pleuroxus and of three related genera (Anomopoda, Chydoridae) in southern Australia and New Zealand. Records of the Australian Museum 43: 291-372.

Frey, D.G. (1998). Expanded description of Leberis aenigmatosa Smirnov (Anomopoda: Chydoridae): a further indication of the biological isolation between western and eastern Australia. Hydrobiologia 367: 3142.

Geddes, M.C. (1981). The brine shrimps Artemia and Parartemia. Comparative physiology and distribution in Australia. Hydrobiologia 81: 169-179.

Geddes, M.C. (1986). Understanding zooplankton communities in farm dams: the importance of predation. In P. De Deckker and W.D. Williams (eds), Limnology in Australia: 387-401. CSIRO: Melbourne.

Geddes, M.C., De Deckker, P., Williams, W.D., Morton, D.W. and Topping, M. (1981). On the chemistry and biota of some saline lakes in Western Australia. Hydrobiologia 82: 201-222.

Gentilli, J. (1972). Australian Climate Patterns. Thomas Nelson, Melbourne.

Geological Survey of Western Australia (1990). Geology and mineral resources of Western Australia. Western Australian Geological Survey, Memoir 3, Perth.

George, R. (1992). Hydraulic properties of groundwater systems in the saprolite and sediments of the wheatbelt, Western Australia. Journal of Hydrology 130: $251-278$

George, R., McFarlane, D. and Nulsen, B. (1997). Salinity threatens the viability of agriculture and ecosystems in Western Australia. Hydrogeology Journal 5: 6--21.

George, R.J., McFarlane, D.J. and Speed, R.J. (1995). The consequences of a changing hydrologic environment for native vegetation in southwestern Australia. In D.A. Saunders, J.L. Craig and E.M. Mattiske (eds), Nature conservation 4: the role of networks, 9-22. Surrey Beatty: Perth.

Growns, J.E., Davis, J.A., Cheal, F., Schmidt, L.G., Rosich, R.S. and Bradley, S.J. (1992). Multivariate pattern analysis of wetland invertebrate communities and environmental variables in Western Australia. Australian Journal of Ecology 17: 275-288.

Halse, S.A. (1981). Faunal assemblages of some saline lakes near Marchagee, Western Australia. Australian Journal of Marine and Freshwater Research 32: 133-142.

Halse, S.A. (2002). Diversity of Ostracoda (Crustacea) in inland waters of Western Australia. Verhandlungen Internationale Vereinigung fur theoretische und angezuandte Limnologie 28: 914-918.

Halse, S.A., Cale, D., Jasinska, E.J. and Shiel, R.J. (2002). Monitoring change in aquatic invertebrate biodiversity: sample size, faunal elements and analytical methods. Aquatic Ecology 36: 395-410.

Halse, S.A., Lyons, M.N. and Pinder, A.M. (2004). Biodiversity patterns and their conservation in wetlands of the Western Australian Wheatbelt. Records of the Western Australian Museum Supplement 67: 337-364.

Halse, S.A. and McRae, J.M. (2001). Calamoecia trilobata n sp (Copepoda: Calanoida) from salt lakes in southwestern Australia. Journal of the Royal Society of Western Australia 84: 5-11.

Halse, S.A. and McRae, J.M. (2004). New genera and species of giant ostracods (Crustacea: Cyprididae) from Western Australia. Hydrobiologia 524: 1-52.

Halse, S.A., Pearson, G.P., McRae, J.M. and Shiel, R.J. (2000). Monitoring aquatic invertebrates and waterbirds at Toolibin and Walbyring Lakes in the Western Australian Wheatbelt. Journal of the Royal Society of Western Australia 83: 17-28.

Halse, S.A., Ruprecht, J.K. and Pinder, A.M. (2003). Salinisation and prospects for biodiversity in rivers and wetlands of south-west Western Australia. Australian Journal of Botany 51: 673-688.

Halse, S.A., Shiel, R.J., Storey, A.W., Edward, D.H.D., Lansbury, I., Cale, D.J. and Harvey, M.S. (2000). Aquatic invertebrates and waterbirds of wetlands and rivers of the southern Carnarvon Basin, Western Australia. Records of the Western Australian Museum, Supplement 61: 217-265.

Halse, S.A., Williams, M.R., Jaensch, R.P. and Lane, J.A.K. (1993). Wetland characteristics and waterbird use of wetlands in south-western Australia. Wildlife Research 20: 103-126. 
Halse, S.A., Vervest, R.M. Munro, D.R., Pearson, G.B. and Yung, F.H. (1992). Annual waterfowl counts in south-west Western Australia: 1989/90. Technical Report 29. Department of Conservation and Land Management, Perth.

Hancock, M.A and Timms, B.V. (2001). Ecology of four turbid clay pans during a filling-drying cycle in the Paroo, semi-arid Australia. Hydrobiologia 479: 95-107.

Hawking, J.H. (2001). An introduction to the identification of aquatic caterpillars (Lepidoptern) found in Australian inland waters. Cooperative Research Centre for Freshwater Ecology, Albury.

Hawkins, B.A., Field, R., Cornell, H.V., Currie, D.J., Guegan, J..F., Kaufman, D.M., Kerr, J.T., Mittelbach, G.G., Oberdorff, T., O'Brien, E.M., Porter, E.E. and Turner, J.R.G. (2003). Energy, water, and broad-scale geographic patterns of species richness. Ecology 84 : $3105-3117$

Hebert, P.D.N and Wilson, C.C. (2000). Diversity of the genus Daphniopsis in the saline waters of Australia. Canndian Joumal of Zoology 78: 794-808.

Hendrich, L. (2001a). A new species of Antiporus Sharp 1882 from peatland swamps of south-western Australia (Coleoptera: Dytiscidae). Linzer Biologische Beitrage 33: 299-308.

Hendrich, L. (2001b). A new species of Hygrobin Latreille, from peatlands of south-western Australia. Koleopterologische Rundschan 71: 17-25.

Hengeveld, R. and Haeck, J. (1982). The distribution of abundance. I. Measurements. Journal of Biogeography 9: 303-316

Herbst, D.B. (2001). Gradients of salinity stress, environmental stability and water chemistry as a templet for defining habitat types and physiological strategies in inland salt waters. Hydrobiologia 466 : 209-219.

Hodgkin, E.P. and Hesp, P. (1998). Estuaries to salt lakes: holocene transformation of the estuarine ecosystems of south-western Australia. Marine and Freshwater Research 49: 183-201

Hopper, S.D. (1979). Biogeographical aspects of speciation in the south-west Australian flora. Ammal Review of Ecology and Systematics 10: 399-422.

Horwitz, P. (1994). Patterns of endemism in the freshwater fauna of the far southern peatlands and shrublands of southwestern Australia. A report prepared for the Australian Heritage Commission and the Heritage Council of Western Australia. Edith Cowan University, Perth.

Horwitz, P. (1997). Comparative endemism and richness of the aquatic invertebrate fauna in peatlands and shrublands of far south-western Australia. Memoirs of the Muscum of Victoria $56: 313-321$.

Huys, R. and Boxshall, G.A. (1991). Copepol erolution. Ray Societv, London.

Jenkins, D.G. and Buikema, A.L. (1998). Do similar communities develop in similar sites? A test with zooplankton structure and function. Ecological Monographs 68: 421-423.

Kay, W.R., Halse, S.A., Sanlon, M.D. and Smith, M.J. (2001). Distribution and environmental tolerances of aquatic macroinvertebrate families in the agricultural zone of southwestern Australia. Iournal of the North American Benthological Society 20: 182-199.

Kay, W.R., Smith, M.J., Pinder, A.M., McRae, J.A., Davis, J.A. and Halse, S.A. (1999). Patterns of distribution of macroinvertebrate families in rivers of north-western Australia. Freshwater Biology 41: 299-316.

Koste, W., Shiel, R.J. and Brock, M.A. (1983). Rotifera of Western Australian wetlands with descriptions of two new species. Hydrobiologia 104: 9-17.

Liehne, P.F.S. (1991). An atlas of the mosquitoes of Western Australia. Health Department of Western Australia, Perth.

Lyons, M.N., Gibson, N., Keighery, G.J. and Lyons, S.D. (2004). Wetland flora and vegetation of the wheatbelt of southwestern Australia. Records of the Western Australian Museum Supplement 67: 39-89.

MacPherson, J.H. (1957). A review of the genus Coxiella Smith, 1894 sensu lato. West Australian Naturalist 5: 191-204.

Maly, E.J., Halse, S.A. and Maly, M.P. (1997). Distribution and incidence patterns of Boeckella, Calamoecia, and Hemiboeckella (Copepoda: Calanoida) in Western Australia. Marine and Freshwater Research 48: 615-621.

Mann, A.W. (1983). Hydrogeology and weathering on the Yilgarn Block, Western Australia - ferrolysis and heavy metals in continental brines. Geochemica et Cosmochemica Acta 47: 181-190.

McFarlane, D.J., George, R.J. and Farrington, P. (1983). Changes in the hydrologic cycle. In R.J. Hobbs and D.A. Saunders (eds), Reintegrating fragmented landscapes: towards sustainable production and nature conservation, 146-189. Springer-Verlag: New York.

Mezquita, F., Roca, J.R. and Wansard, G. (1999). Moulting, survival and calcification: the effects of temperature and water chemistry on an ostracod crustacean (Herpetocypris intermedia) under experimental conditions. Archiv fur Hydrobiologie 146: 219-238.

Mitchell, B.D. (1986). Entomostracan zooplankton communities of Australian freshwater lakes and ponds. In P. De Deckker and W.D. Williams (eds), Limnology in Australia, 369-386. CSIRO: Melbourne.

NLWRA (2001). Australian dryland salinity assessment 2000. National Land and Water Resources Audit, Canberra.

Northcote, K.H. (1971). A factual key for the recognition of Australian soils. Rellim Technical Publications, Glenside, South Australia.

Pen, L.J. (1997). A systematic overview of environmental values of wetlands, rivers and estuaries of the Busselton-Walpole region WRAP 7. Water and Rivers Commission, Perth.

Pinder, A.M. (2001). Notes on the diversity and distribution of Australian Naididae and Phreodrilidae (Oligochaeta: Annelida). Hydrobiologia 463: 49-64.

Pinder, A.M. (2002). New species and records of Phreodrilidae (Annelida: Clitellata) from Western Australia. Records of the Western Australian Museum 21: $307-313$.

Pinder, A.M. and Brinkhurst, R.O. (1997). A review of the Phreodrilidae (Annelida: Oligochaeta: Tubificida) of Australia. Invertebrate Taxonomy 11: 443-523. 
Pinder, A.M. and Halse, S.A. (2001). Two new species of Ainudrilus (Clitellata: Tubificidae) from south-western Australia, with notes on Ainudrilus nharna Pinder and Brinkhurst. Records of the Western Australian Museum 21: $1-7$

Pinder, A.M., Halse, S.A., McRae, J.M. and Shiel, R.J. (2002). Halophile aquatic invertebrates in the Wheatbelt region of south-western Australia. Verhandlungen Internationale Vereinigung Limnologie 28: $1687-1694$

Pinder, A.M., Halse, S.A., McRae, J.M. and Shiel, R.J. (in press). Occurrence of aquatic invertebrates of the Wheatbelt region of Western Australia in relation to salinity. Hydrobiologia.

Pinder, A.M., Halse, S.A., Shiel, R.J. and McRae, J.M. (2000). Granite outcrop pools in south-western Australia: foci of diversification and refugia for aquatic invertebrates. Journal of the Royal Society of Western Australia 83: 149-161.

Pinel-Alloul, B., Niyonsenga, T. and Legendre, P. (1995). Spatial and environmental components of freshwater zooplankton structure. Ecoscience 2: 1-19.

Pusey, B.J. and Edward, D.H. (1990). Limnology of the southern acid peatflats, south-western Australia. Journal of the Royal Society of Western Australia 73: 29 46.

Radke, L.C., Howard, K.W.F. and Gell, P.A. (2002). Chemical diversity in south-eastern Australian saline lakes I: Geochemical causes. Marine and Freshwater Research 53: 941-959.

Radke, L.C., Juggins, S., Halse, S.A., De Deckker, P. and Finston, T. (2003). Chemical diversity in south-eastern Australian saline lakes II: biotic implications. Marine and Freshwater Research 54: 895-912.

Rippingale, R. (1981). The ecology of plankton fauna in saline river pools. Hydrobiologia 81-82: 223-231.

Sarma, S.S., Elguea-Sanchez, B. and Nandini, S. (2002). Effect of salinity on competition between the rotifers Brachionus rotundiformis Tschugunoff and Hexarthra jenkinne (De Beauchamp) (Rotifera). Hydrobiologia 474: 183-188.

Segers, H. and Shiel, R.J. (2003). Microfaunal biodiversity in a biodiversity hotspot: new rotifers from Western Australia. Zoological Studies 42: 516-521.

Shepherd, D.P., Beeston, G.R. and Hopkins, A.J.M. (2001). Native vegetation in Western Australia: Extent, type and status. Technical Report 249. Department of Agriculture, South Perth.

Shiel, R.J. (1995). A Guide to identification of rotifers, cladocerans and copepods from Australian inland waters. Identification Guide No. 3. CRC for Freshwater Ecology and The Murray Darling Freshwater Research Centre.

Shiel, R.J., Green, J.D. and Nielsen, D.L. (1998). Floodplain biodiversity: why are there so many species? Hydrobiologia 387: 39-46.

Short, R. and McConnell, C. (2001). Extent and impacts of dryland salinity. Resource Management Technical Report 202. Agriculture Western Australia, Perth.

St. Clair, R.M. (2000). Preliminary keys for the identification of Australian caddisfly laroae of the family Leptoceridae. Identification Guide No. 27. Cooperative Research Centre for Freshwater Ecology, Albury.
St. Clair, R.M. (2002). Western Australian Triplectidinae (Trichoptera: Leptoceridae): descriptions of the female of Triplectides niveipennis and larvae belonging to four genera. Records of the Western Australian Museum 21: $111-127$.

Storey, A.W. (1998). Assessment of the nature conservation values of the Byenup-Muir Peat Swamp system, south-western Australia: Physico-chemistry, aquatic macroinvertebrates and fishes. An unpublished report for the Department of Conservation and Land Management. Wetland Research and Management, Perth.

Storey, A.W., Halse, S.A. and Shiel, R.J. (1993). Aquatic invertebrate fauna of the Two Peoples Bay area, south-western Australia. Journal of the Royal Society of Western Australia 76: 25-32.

Tabachnik, B.G. and Fidell, L.S. (1983). Using multivariate statistics. Harper and Row, New York.

Thackway, R. and Cresswell, I. (1995). An interim biogeographic regionalisation for Australia: a framework for setting priorities in the national reserves system. Cooperative program version 4 . Australian Nature Conservation Agency, Canberra.

Thomsen, J.B. (1999). Looking for the hotspots. World Conservation 2/99: 6-7.

Timms, B.V. (1983). A study of benthic communities in some shallow saline lakes of western Victoria, Australia. Developments in Hydrobiology 16: 165-168.

Timms, B.V. (1993). Saline lakes of the Paroo, inland New South Wales, Australia. Hydrobiologia 267: 269-289.

Timms, B.V. (2001). Limnology of the intermittent pools of Bells Creek, Paroo, arid Australia, with special reference to biodiversity of invertebrates and succession. Proceedings of the Linnean Society of New South Wales 123: 193-213.

Timms, B.V. (2002). The fairy shrimp genus Branchinella Sayce (Crustacea: Anostraca: Thamnocephalidae) in Western Australia, including a description of four new species. Hydrobiologia 486: 71-89.

Timms, B.V. and Boulton, A.J. (2001). Typology of aridzone floodplain wetlands of the Paroo River (inland Australia) and the influence of water regime, turbidity, and salinity on their aquatic invertebrate assemblages. Archiv fur Hydrobiologie 153: 1-27.

Walshe, T.V., Halse, S.A., McKenzie, N.L. and Gibson, N. (2004). Toward identification of an efficient set of conservation recovery catchments for Western Australian wheatbelt biodiversity. Records of the Western Australian Museum Supplement 67: 365-384.

Watts, C.H.S. (1978). A revision of the Australian Dytiscidae (Coleoptera). Australian Journal of Zoology, Supplementary Series 57: 1-166.

Watts, C.H.S. (1997). Four new species of Antiporus Sharp (Coleoptera, Dytiscidae) from Australia, with notes on A. femoralis (Boh.) and A. interrogationis (Clark). Records of the South Australian Museum 30: 35-42.

Watts, C.H.S. and Pinder, A. (2000). Two new species of Antiporus Sharp from Western Australia (Coleoptera: Dytiscidae). Records of the South Australian Museum 33: 17-19.

Williams, W.D. (1981). The limnology of saline lakes in Western Victoria. Hydrobiologia 82: 233-259. 
Williams, W.D. (1987). Salinisation of rivers and streams: An important environmental hazard. Ambio 16: 180 185.

Williams, W.D. (1998a). Diversity and evolution of the fauna of the dryland wetlands. In A.J. McComb and J.A. Davis (eds), Wetlands for the future: INTECOL's 5th International Wetlands Conference, 1996, 167-171. Gleneagles Press: Adelaide.

Williams, W.D. (1998b). Salinity as a determinant of the structure of biological communities in salt lakes. Hydrobiologia 381: 191-201.

Williams, W.D. (1999). Salinisation: A major threat to water resources in the arid and semi-arid regions of the world. Lakes and Reservoirs: Research and Management 4: 85-91.
Williams, W.D. (2000). Biodiversity in temporary wetlands of dryland regions. Verhandlungen Internationale Vereinigung fur theoretische und angezoandte Limnologie 27: 141-144.

Williams, W.D., Boulton, A.J. and Taafe, R.G. (1990). Salinity as a determinant of salt lake fauna: a question of scale. Hydrobiologia 197: 257-266.

Williams, W.D. and Mellor, M.W. (1991). Ecology of Coxiella (Mollusca, Gastropoda, Prosobranchia), a snail endemic to Australian salt lakes. Palaeogeography, Palaeoclimatology and Palaeoecology 84: 339-355.

\section{Electronic appendices are on $C D$ inside the back cover}

